\title{
Reflective and Reflexive Action Control in Patients With Frontal Brain Lesions
}

\author{
Angelika Lengfelder \\ Universität München
}

\author{
Peter M. Gollwitzer \\ Universität Konstanz and New York University
}

\begin{abstract}
Two types of action control derived from the model of action phases $(H$. Heckhausen \& P. M. Gollwitzer, 1987) were analyzed in patients with frontal lesions, patients with nonfrontal lesions, and university students. In Study 1, reflective action control in terms of goal selection was assessed, and impaired deliberation was found in patients with frontal lesions. Study 2 assessed reflexive action control in terms of automatic action initiation as a result of forming implementation intentions (P. M. Gollwitzer, 1999). All participants sped up their responses to critical stimuli by forming implementation intentions. Moreover, lesion patients with weak performances on the Tower of Hanoi ( $\mathrm{TOH}$ ) task did worse than patients with strong TOH performances in Study 1 but better than control participants in Study 2. Findings are interpreted as a functional dissociation between conscious reflective action control and automatic reflexive action control.
\end{abstract}

Patients with frontal lobe damage are often unable to cope with everyday life despite their unaffected performance in tests of intelligence, language, memory, and perception (Grattan \& Eslinger, 1991). This discrepancy has stimulated various models describing the planning and action control deficits in patients with frontal brain lesions.

For a long time, the frontal lobes have been considered to be involved in regulating and programming behavior (e.g., Harlow, 1896/1993; Luria, 1962, 1973; Pribram, 1987; Pribram \& Tubbs, 1967). Hierarchical models of brain functioning (Stuss \& Benson, 1986; Tranel, Anderson, \& Benton, 1994) assume that executive functions (including anticipation, goal selection, planning, monitoring, and use of feedback), located in the prefrontal cortex, control the lower level fixed functional systems (e.g., attention, memory). Other models make a distinction between explicit and im-

Angelika Lengfelder, Institut für Pädagogische Psychologie und Empirische Pädagogik, Universität München, München, Germany; Peter M. Gollwitzer, Fachgruppe Psychologie, Universität Konstanz, Konstanz, Germany, and Department of Psychology, New York University.

This research was supported by the Max-Planck Research Award of the Max-Planck-Society and the Humbold Society to Peter M. Gollwitzer, as well as the Max-Planck-Institute for Psychological Research. We greatly appreciate the help of Gabi Matthes-von Cramon in collecting the data of the neurological patients. We are particularly indebted to Detlef von Cramon, who was the chair of the Unit of Neuropsychological Rehabilitation at the Krankenhaus München Bogenhausen at the time of the study, for providing access to the patients participating in the present study. Thanks are due to Irmina Quenzel and Maya Böhm, who assisted in collecting and analyzing the data.

Correspondence concerning this article should be addressed to Angelika Lengfelder, Institut für Pädagogische Psychologie und Empirische Pädagogik, LMU München, Leopoldstr. 13, D-80802 München, Germany. Electronic mail may be sent to lengfeld@ mip.paed.uni-muenchen.de. plicit control of action. Processes of the frontal lobes are assumed to be involved whenever a new activity is being learned. However, when an activity has become routine, other brain regions-especially subcortical ones-are said to determine action. For instance, Norman and Shallice (1986) suggested that two processes operate in the selection and control of action: contention scheduling (CS) and the supervisory attentional system (SAS). CS acts through lateral activation and inhibition of action schemas depending on their activation value, and, thus, behavior is triggered automatically. The SAS, in contrast, provides the conscious attentional control of action selection by modulating the activation and inhibition values of action schemas, and thus is assumed to be responsible for planning, decision making, and monitoring behavior. Whereas the SAS is thought to be located in the frontal lobes, CS is assumed to take place in other regions of the brain (possibly the basal ganglia). To support their model, Norman and Shallice (1986) referred to slips of action (Reason, 1987) that occur when action is triggered by CS unmonitored by the SAS.

Indeed, in patients with frontal lesions, heightened frequencies of action slips have been documented in research on utilization behavior (Fukui, Hasegawa, Sugita, \& Tsukagoshi, 1993; Lhermitte, 1983; Shallice, Burgess, Schon, \& Baxter, 1989), imitation behavior (Lhermitte, Pillon, \& Serdaru, 1986; Luria, 1973), environmental dependency (Lhermitte, 1986), novelty preference (D. S. Levine, Leven, \& Prueitt, 1992), and capture errors in sequencing (Della Malva, Stuss, D'Alton, \& Willmer, 1993). In other words, the intentional goal-directed behaviors of patients with frontal brain lesions are easily disrupted and replaced by routinized and habitual behaviors when the current situation entails the respective triggering stimuli.

Even though defective planning and action control after frontal lobe lesions are well documented in the neuropsychological literature (case studies: e.g., Cockburn, 1995; von Cramon \& Matthes-von Cramon, 1994; Damasio, 1985; Konow \& Pribram, 1970; overviews: e.g., Fuster, 1989; 
Shallice, 1988; Stuss \& Benson, 1986), the concepts of action control and planning are used inconsistently and are only vaguely defined. The neuropsychological assessment of planning also suffers from conceptual vagueness. For example, Tower puzzles are commonly used to assess frontal functions, even though these tasks do not always successfully identify patients with frontal lobe dysfunctions (Levin, Goldstein, Williams, \& Eisenberg, 1991; Shallice \& Burgess, 1991). Still, there is evidence of impaired performance on Tower puzzles after frontal lobe lesions (e.g., Owen, Downes, Sahakian, Polkey, \& Robbins, 1990). In positron emission tomography (PET) and single photon emission computed tomography (SPECT) studies with normal participants, dorsolateral frontal involvement was found during Tower of London performance (Morris, Ahmed, Syed, \& Toone, 1993; Rezai et al., 1993).

Accordingly, Tower puzzles seem to assess frontal functions, but it is not clear which functions are assessed. For diagnostic purposes, Tower puzzles are often used to assess the ability to look ahead in planning (e.g., Morris et al., 1993), but they are also used to assess procedural learning (Saint-Cyr, Taylor, \& Lang, 1988), which leads to basal ganglia activation in addition to activation in frontal areas (Owen, Doyon, Dagher, Sadikot, \& Evans, 1998). Goel and Grafman (1995) recently analyzed the task demands of Tower of Hanoi type problems and argued that it is neither planning nor sequencing that is assessed in these problems but rather the ability to solve goal-subgoal conflicts. Finally, findings from cognitive psychology suggest that Tower puzzles indeed measure different cognitive processes that relate to various stages of strategy acquisition: conscious deliberation (participants use reasoned strategies when first confronted with the task), sequencing, and procedural learning (Simon, 1975; Kotovsky, Hayes, \& Simon, 1985).

Jeannerod (1997) recently suggested that planning is "a broad process which can be analyzed and decomposed into more elementary operations" (p. 133). We share this view and maintain that it is important to explicate the concept of planning because it is likely that not all aspects of planning are affected to the same degree by frontal brain lesions. In the present article, we put this hypothesis to the test by exploiting recent advances in action control theorizing. In their model of action phases, Heckhausen and Gollwitzer (1987; Gollwitzer, 1990; Heckhausen, 1991) suggested that intentional control of action necessitates the successful solving of four different tasks. First, people need to set preferences between their wishes and desires by engaging in intensive deliberation of the feasibility and desirability of the potential goals and then turn the most preferred desires into binding goals. Second, once such goal decisions have been made, the next task is to make plans for when, where, and how one intends to implement the chosen goal and to initiate the implementation of goal-directed actions. Third, ongoing goal-directed actions need to be monitored and brought to a successful ending. Fourth, to be able to decide on further goal striving, one needs to evaluate whether the attained outcomes match the originally desired outcomes.
Gollwitzer (1993, 1999) expanded the theorizing on the second task of the action phases model (i.e., planning the initiation of goal-directed actions) by suggesting a distinction between so-called goal intentions ("I intend to achieve $x$ !") and implementation intentions ("And if I encounter the situation $y$, I will perform the goal-directed behavior $z$ !"). Goal intentions turn desires into binding goals, whereas implementation intentions plan how the goal is going to be attained. Implementation intentions are thus formed in the service of goal intentions and belong to the planning phase of goal attainment. It is assumed that implementation intentions delegate the control of one's actions to the specified anticipated future situations, which, once encountered, initiate the intended goal-directed behaviors automatically. Research has demonstrated that behavior specified in implementation intentions is initiated immediately, efficiently, and without conscious intent (Gollwitzer, 1993, 1999; Gollwitzer \& Brandstätter, 1997; Gollwitzer \& Schaal, 1998), all of which are characteristic features of automatic action control (Bargh, 1997).

The selection of new goals (i.e., the formation of new goal intentions) would certainly demand conscious reflection, however. Assuming that frontal lobe injuries impair conscious action control processes, patients with a frontal lobe lesion should evidence less deliberation when making goal decisions compared with people without a frontal lobe injury. In Study 1, we tested this hypothesis by confronting patients with frontal lobe lesions, patients with nonfrontal lobe lesions, and university students with numerous different behavioral choice situations that demanded a goal decision.

In contrast, because automatic control of habitualized behavior remains intact after frontal lobe damage, patients with frontal lobe lesions should benefit as much from having formed implementation intentions as control participants. Even though the formation of implementation intentions involves conscious reflection, the initiation of the goal-directed behaviors specified in implementation intentions may solely rely on automatic process. In Study 2, we therefore helped patients with frontal brain lesions, patients with nonfrontal brain lesions, and university students to form implementation intentions and then observed whether the intended goal-directed behavior became automatically controlled to the same degree in all groups.

In both studies, we analyzed complex processes of action control in heterogeneous samples. Therefore, we used repeated measures designs (i.e., within designs) because they most effectively control for relevant premorbid interindividual differences (e.g., education, life experiences, cognitive abilities, sex, age, handedness) and interindividual neurological and neuropsychological differences (e.g., lesion location, deficiencies in cognitive processing, effects of rehabilitation). Accordingly, both studies use mixed between-within factorial experimental designs that allow for comparisons of individual patterns of behavior between patients with frontal brain lesions, other brain-injured patients, and noninjured college students. Within these groups, we compared performances on different types of tasks (i.e., 
decision problems of various difficulty in Study 1 and different types of preparing a critical response in Study 2).

\section{Study 1: Reflective Action Control}

Defective decision making is considered to be a typical frontal lobe dysfunction. Problems in decision making have been documented in case studies (e.g., Damasio, Tranel, \& Damasio, 1991; Eslinger \& Damasio, 1985; Saver \& Damasio, 1991), whereas experimental studies directly addressing decision making are rare (Bechara, Damasio, Damasio, \& Anderson, 1994; Coolidge \& Griego, 1995; Decary \& Richer, 1995). Still, experimental studies on problem solving imply that deliberation is hampered in patients with frontal lobe lesions. Moreover, deficiencies in tasks of subject-ordered pointing and recency discrimination not only may indicate defective temporal organization (McAndrews \& Milner, 1991; Milner, Petrides, \& Smith, 1985; Petrides \& Milner, 1982) but also may hint at impaired conscious deliberation (Wiegersma, van der Scheer, \& Hijman, 1990). Finally, an inferior performance in the Tower of Hanoi can be interpreted as a deficiency in making goal-subgoal decisions (Goel \& Grafman, 1995).

The present experiment directly addresses the issue of deliberating a decision. Participants were confronted with behavioral choice situations that varied in terms of the number and complexity of aspects that needed to be taken into account to arrive at a reasoned decision. The ability to deliberate adequately was thought to be reflected in a close link between the perceived difficulty of the problem and the time spent deliberating on the problem. If this ability is lacking, no positive relation between the perceived difficulty of the problem and the time spent deliberating should prevail. Moreover, the classic result that intensive deliberation increases uncertainty (Mann \& Taylor, 1970) should fail to emerge.

We ran four groups of participants: patients with frontal lobe lesions, patients with nonfrontal lobe lesions, and two control groups consisting of university students. In participants with intact frontal lobe functioning, the deliberation time was expected to correlate positively with the perceived difficulty of the presented choice problems and negatively with the rated certainty of the decisions made, whereas no systematic relations were predicted for patients with frontal lobe lesions.

\section{Method}

\section{Participants}

The clinical sample consisted of 30 brain-injured patients of the Krankenhaus Bogenhausen, München, Germany. Eighteen patients had a frontal brain lesion ( 7 women, 11 men) and 12 had a nonfrontal brain lesion ( 2 women, 10 men). In the frontal lobe (FL) group, the mean age was 32.50 years $(S D=12.00)$, and in the nonfrontal lobe (NFL) group, the mean age was 42.92 years $(S D=13.93)$. As nonclinical controls for the frontal lobe (CFL) group, 7 female and 11 male university students were randomly selected from the participant pool of the Max-Planck-Institute for Psychological Research in Munich, Germany; the same procedure was applied to create a control group for the nonfrontal lobe (CNFL) group as well. The mean age of the two control groups was 25.33 years $(S D=2.97)$ and 24.67 years $(S D=1.83)$, respectively.

Patients' lesions (see Appendix A for single case information) in the FL group were due to head injury $(n=11)$ and cerebrovascular disease $(n=7)$. In the NFL group, head injury $(n=4)$, cerebrovascular disease $(n=6)$, and hypoxia $(n=2)$ were considered to be responsible for the brain lesions. Clinical data about lesion location, etiology, handedness, symptoms of paralysis, and measures of cognitive and motor functions were available in the hospital's files. Patients were selected on the criteria that they would have no reading difficulties (e.g., alexia, aphasia, or fixation problems), would possess an intact understanding of instruction, and would be able to use a pencil with one hand. All patients had more than 40 days of recovery. Twenty-five participants had experienced more than 6 months of recovery and thus qualified as chronic patients (Karnath, Wallesch, \& Zimmermann, 1991).

\section{Procedure and Materials}

As depressive states are known to increase decision times ( $\mathrm{Pi}$ etromonaco \& Rook, 1987), we asked participants at the outset of the experiment to fill out two reliable depression scales: the Beck Depression Inventory (BDI; Beck, Rush, Shaw, \& Emery, 1986; Beck \& Steer, 1987) and the Center for Epidemiological Studies Depression scale (CES-D; Radloff, 1977). Participants then received a booklet that contained 20 decision problems of equal length (15 lines of text each) concerning various aspects of life (including professional and social issues, shopping, eating, financial investments, transportation or moving; see Appendix B for examples). In constructing the decision problems, we took steps to avoid issues that are gender biased or too far removed from the patients' everyday life. To produce enough variance in perceived difficulty of the decision problems, we constructed problems at different levels of complexity. This was achieved by varying the number of aspects requiring deliberation (e.g., uncertainty of consequences, questionable attractiveness of these consequences, or questionable reversibility of these consequences).

Each problem was embedded in a short story (of equal length) and presented on a different page. Participants were instructed to read each problem and to imagine that they were experiencing it in person. They were told to think about the decision alternatives presented after having read the text and to take as much time as necessary to make a decision. For each decision problem, two decision alternatives were listed, and participants were asked to pick their choice. Immediately after each decision, participants had to answer questions that assessed the perceived difficulty of the decision problem at hand as well as the certainty of having made the correct decision using 10-point rating scales $(0=$ not at all difficult, $9=$ very difficult; and $0=$ not at all certain, $9=$ very certain, respectively). The decision time for each problem was defined as the time from turning the page to marking the chosen alternative. Participants did not know that their decision times were recorded while they worked on the decision problems.

\section{Design}

A mixed-factorial design was used, with group (FL, NFL, CFL, $\mathrm{CNFL}$ ) as the between factor and decision problem (Problems $1-20$ ) as the within factor. 


\section{Results}

\section{Equivalence of Groups}

Before analyzing the individual patterns of behavior (using individual correlation coefficients), we compared group means to explore the differences between groups.

Depression. To assure a valid assessment of depression, we computed a correlation coefficient for the two scales $(r=.65)$. The four groups (FL, NFL, CFL, and CNFL) did not differ in terms of their depression levels as assessed by the two scales, $F_{\mathrm{BDI}}(3,56)=1.68, n s ; F_{\mathrm{CES}-\mathrm{D}}(3,56)=$ 1.22 , ns. BDI scores in the patient group $\left(M_{\mathrm{FL}}=12.50\right.$, $\left.S D=11.72 ; M_{\mathrm{NFL}}=11.92, S D=9.58\right)$ were slightly above normal (normal scores are $\leq 11$; Beck \& Steer, 1987 ), which may be a reaction to the lesion or the experienced abrupt life changes. However, these scores are far below clinical relevance (clinically relevant scores are $\geq$ 18; Beck \& Steer, 1987).

Problem difficulty and certainty of decision. To assess the validity of our measures of problem difficulty and certainty of decision, we correlated the perceived difficulty with the rated certainty. The classic finding of a negative relation between certainty and task difficulty (in the sense that easier decisions lead to higher certainty ratings; e.g., Peterson \& Pitz, 1988) was confirmed in all groups $\left(r_{\mathrm{FL}}=\right.$ $\left.-.73 ; r_{\mathrm{NFL}}=-.71 ; r_{\mathrm{CFL}}=-.81 ; r_{\mathrm{CNFL}}=-.46\right)$.

We used the students' ratings of the difficulty of the decision problems to classify the 20 problems into three difficulty groups: low, medium, and high. The reliability of this grouping was checked by computing Cronbach's alpha coefficients of internal consistency. The reliability of the scores of perceived difficulty (FL $M d n=.66$; NFL $M d n=$ .74; CFL $M d n=.51 ;$ CNFL $M d n=.72$ ) and rated certainty $(\mathrm{FL} M d n=.74 ; \mathrm{NFL} M d n=.72 ; \mathrm{CFL} M d n=.52 ; \mathrm{CNFL}$ $M d n=.55)$ turned out to be satisfactory. When we computed a 4 (groups: FL, NFL, CFL, CNFL) $\times 3$ (level of difficulty: low, medium, high) analysis of variance (ANOVA) on the mean perceived difficulty of the decision problems, a highly significant main effect of level of perceived difficulty was observed, $F_{\text {linear trend }}(1,56)=108.00$, $p<.001, \eta^{2}=.66$, which was not qualified by an interaction with group of participants, $F_{\text {linear trend }}(3,56)=1.22, n s$.
This pattern of data suggests that the lesion patients perceived the increase in difficulty of the 20 decision problems just as clearly as the university students did. An analogous analysis conducted on the dependent variable of rated certainty yielded very similar results: effect of problem difficulty, $F_{\text {linear trend }}(1,56)=55.90, p<.001, \eta^{2}=$ .50 ; interaction with the group factor, $F_{\text {linear trend }}(3,56)$ $=1.08, n s$.

Decision times. We also computed a 4 (groups: FL, NFL, CFL, CNFL) $\times 3$ (level of difficulty: low, medium, high) ANOVA on decision times. It yielded a highly significant main effect for the level of difficuity, $F_{\text {linear trend }}(1$, $56)=4.79, p<.05$, accounting for only $8 \%$ of variance $\left(\eta^{2}=.08\right)$, which was not qualified by an interaction effect with the group factor, $F_{\text {linear trend }}(3,56)=1.55$, ns. This time, however, there was a significant main effect of group, $F(3,56)=5.71, p<.01$. To understand the nature of the group differences, we compared the clinical groups with their respective student control groups. Whereas both groups of lesion patients responded more slowly than the respective control groups (all $t \mathrm{~s}>2.70, p \mathrm{~s}<.01$ ), no difference was found between the two lesion groups, $t(28)<0.35, n s$. This pattern of data suggests that all lesion patients needed more time to make decisions than university students, which may be due not only to differences in age but also to a general slowing of information processing in some patients. In the central analyses (see below), we therefore focused on the relation between dependent variables within each individual participant. These individual patterns of data stay unaffected from potential biases rooted in interindividual differences in speed of processing, age, sex, IQ, and so forth.

\section{Amount of Deliberation}

The relation between perceived difficulty and decision time. In a first step, over all 20 decision problems a Pearson correlation coefficient between a person's perceived difficulty ratings and that person's decision times was computed for each individual participant. We then standardized these correlation coefficients by transforming them into Fisher's Zs. When computing a mean $Z$ for each

Table 1

Mean Correlation Between Decision Time and Perceived Problem Difficulty as Well as Rated Certainty of Decision for the Different Experimental Groups

\begin{tabular}{|c|c|c|c|c|c|c|c|c|}
\hline \multirow[b]{2}{*}{ Correlation } & \multicolumn{2}{|c|}{ FL } & \multicolumn{2}{|c|}{ NFL } & \multicolumn{2}{|c|}{ CFL } & \multicolumn{2}{|c|}{ CNFL } \\
\hline & $M$ & $\overline{S D}$ & $M$ & $\overline{S D}$ & $M$ & $\overline{S D}$ & $M$ & $S D$ \\
\hline $\begin{array}{l}\text { Decision time and perceived } \\
\text { problem difficulty }\end{array}$ & $.12 \mathrm{a}$ & .25 & $.18_{\mathrm{a}, \mathrm{c}}$ & .39 & $.38_{\mathrm{b}}$ & .30 & $.35_{b, c}$ & .34 \\
\hline $\begin{array}{l}\text { Decision time and rated } \\
\text { certainty }\end{array}$ & $-.08_{a}$ & .30 & $-.24_{b}$ & .33 & $-.26 \mathrm{c}$ & .27 & $-.23_{b . c}$ & .25 \\
\hline
\end{tabular}

Note. The numbers represent Fisher's Zs. Means in the same row that do not share a common subscript differ at $p<.05$ in planned single contrasts ( $t$ tests comparing FL vs. NFL, FL vs. CFL, NFL vs. CNFL, CFL vs. CNFL). FL = patients with frontal lobe lesion; NFL = patients with nonfrontal lobe lesion; $\mathrm{CFL}=$ student control group for $\mathrm{FL} ; \mathrm{CNFL}=$ student control group for NFL. 
Table 2

Mean Correlation Between Decision Time and Perceived Problem Difficulty

as Well as Rated Certainty of Decision as a Function of Performance on the Tower of Hanoi (TOH) Task

\begin{tabular}{|c|c|c|c|c|c|c|c|c|}
\hline \multirow[b]{3}{*}{ Correlation } & \multicolumn{4}{|c|}{ Lesion patients } & \multicolumn{4}{|c|}{ Students } \\
\hline & \multicolumn{2}{|c|}{$\begin{array}{l}\text { Weak TOH } \\
\text { performance }^{\text {a }}\end{array}$} & \multicolumn{2}{|c|}{$\begin{array}{l}\text { Strong } \mathrm{TOH} \\
\text { performance }^{\mathrm{b}}\end{array}$} & \multicolumn{2}{|c|}{$\begin{array}{l}\text { Weak TOH } \\
\text { performance }\end{array}$} & \multicolumn{2}{|c|}{$\begin{array}{c}\text { Strong TOH } \\
\text { performance }^{\mathrm{b}}\end{array}$} \\
\hline & $M$ & $\overline{S D}$ & $M$ & $\overline{S D}$ & $M$ & $S D$ & $M$ & $S D$ \\
\hline $\begin{array}{l}\text { Decision time and } \\
\text { perceived task difficulty }\end{array}$ & $.06_{\mathrm{a}}$ & .21 & $.36_{\mathrm{b}}$ & .43 & $.33_{\mathrm{c}}$ & .29 & $.38_{\mathrm{b}, \mathrm{c}}$ & .16 \\
\hline certainty & $-.04_{\mathrm{a}}$ & .19 & $-.37_{\mathrm{b}}$ & .42 & $-.29_{c}$ & .26 & $-.29_{\mathrm{b}, \mathrm{c}}$ & .31 \\
\hline
\end{tabular}

Note. The numbers represent Fisher's Zs. Means in the same row that do not share a common subscript differ at $p<.05$ in planned single contrasts ( $t$ tests). Student participants were randomly assigned to the weak versus strong TOH control groups.

${ }^{a} n=19 .{ }^{b} n=7$.

of the four groups (FL, NFL, CFL, CNFL), we found that the FL group ( $M=.12, S D=.25, n=17)$ showed a significantly weaker mean $Z$ than the respective student control group $(M=.38, S D=.30, n=17), t(33)=2.81$, $p<.01$, whereas the NFL group $(M=.18, S D=.39, n=$ 12) did not differ significantly from the respective student control group $(M=.35, S D=.34, n=12), t(22)=1.17$, $n s$ (see Table 1). Moreover, we checked for the homogeneity of variances of the Zs, but no difference between groups was found-Levene's test for homogeneity: $F(3,55)$ $=1.17$, ns.

The relation between certainty ratings and decision times. For each of the four groups, we computed mean Fisher's $Z$ s following the same procedure as described above. The FL group $(M=-.08, S D=.30, n=18)$ tended to show a significantly smaller negative relation between certainty ratings and decision times than the respective student control group $(M=-.26, S D=.27, n=18)$, $t(34)=1.89, p=.07$. No differences were observed between the NFL group $(M=-.24, S D=.33, n=12)$ and the respective student control group $(M=-.23, S D=.25$, $n=12$ ). Both groups showed a clear negative relation between decision times and certainty ratings, $t(22)=0.05$, $n s$ (see Table 1). Again, Levene's test showed homogeneity of variances in the four groups, $F(3,56)=0.02$, $n s$.

\section{Grouping Lesion Patients by Their Tower of Hanoi (TOH) Performance}

The hospital files identified patients as either weak or strong performers on the TOH task. When we analyzed the relation between decision times and perceived task difficulty, we observed no relation in the weak performing group ( $n=19$, mean $Z=.06, S D=.21$ ) and a strong positive relation in the strong performing group $(n=7$, mean $Z=$ $.36, S D=.43$; sec Table 2 ). The difference between the mean Zs was statistically significant, $t(24)=2.44, p<.05$. When comparing the strong performing patients with a randomly selected student control group of the same size $(n=7$, mean $Z=.38, S D=.16)$, we observed no signif- icant difference, $t(12)=0.12, n s$. A significant difference emerged, however, when patients showing a weak performance on the TOH task were compared with a randomly selected control group of 19 university students (mean $Z=$ $.33, S D=.29), t(36)=3.35, p<.01$.

With respect to the relation between decision times and rated certainty, the comparison of patients with weak and strong performances on the TOH task revealed a similar pattern of data. As can be seen in Table 2, patients with weak performances $(n=19$, mean $Z=-.04, S D=.19$ ) showed no meaningful relation, whereas patients with strong performances $(n=7$, mean $Z=-.37, S D=.42$ ) showed a marked negative relation, $t(24)=2.83, p<.01{ }^{1}$ Again, random samples from the student control group were compared with the two patient groups. Patients with strong performances on the TOH task did not differ from a student control group of the same sample size (mean $Z=-.30$, $S D=.31), t(12)=0.36$, ns. However, patients with weak performances on the TOH task differed significantly from the student control group (mean $Z=-.29, S D=.26$ ), $t(36)=3.48, p<.01$. These findings suggest that the TOH task and our decision task may rely on similar processes of conscious action control.

\section{Discussion}

Whereas both university students and patients with nonfrontal brain lesions evidenced a positive relation between perceived problem difficulty and decision time as well as a negative relation between decision certainty and decision time, no such relations were observed in patients with lesions in the frontal cortex. Assuming that difficult deci-

\footnotetext{
${ }^{1}$ Because of the inhomogeneity of variances (Levene's test: $F=8.87, p<.01)$ and the difference in sample size, we suspected that this $t$ test would not be reliable and therefore an additional Mann-Whitney $U$ test was performed. Mean rank was 15.32 in the group of patients with defective deliberative planning and 8.57 in the group of patients with intact deliberative planning, $U=32.0$, $z=-1.99, p<.05$.
} 
sions are commonly associated with more intensive deliberation than are easy decisions, the lack of a relation between decision time and perceived problem difficulty as well as between decision time and rated certainty as observed in the FL group suggests that these patients failed to engage in intensive deliberation.

This conclusion is supported by the lack of a relation between perceived problem difficulty and decision time as well as between decision certainty and decision time, particularly in those lesion patients with weak $\mathrm{TOH}$ performances. Patients with strong TOH performances produced a pattern of results similar to a random sample of university students. These findings also suggest that the mental processes required to successfully perform the TOH task (at least those at the early stages of performance) are similar to the processes of conscious deliberation that precede behavioral choices in everyday life.

Any form of deliberation starts with the encoding of relevant information, and, because there is evidence for encoding and retrieval deficiencies in patients with frontal brain lesions (e.g., concerning source memory [Janowsky, Shimamura, \& Squire, 1989], temporal organization of memory [Fuster, 1989; Johnson, O'Connor, \& Cantor, 1997], and monitoring of encoding and retrieval [Stuss \& Benson, 1986]), encoding of the relevant information itself rather than deliberation may have been impaired in the present study. The pattern of data, however, speaks against this view because patients with frontal brain lesions did not differ from the other groups of participants in terms of the perceived difficulty of the decision problems. Although patients with frontal lesions were sensitive to the difficulty levels of the decision problems, they failed to adjust the amount of deliberation. In line with our interpretation of the present data, Saver and Damasio (1991) observed that in tasks of decision making, frontal lobe patients are not deficient in the encoding and retrieval of information. Further support comes from the classic findings of a dissociation between cognition and action in some patients with frontal brain lesions who successfully repeat received instructions and provide the correct verbal response but fail to produce the respective behavior (Milner, 1963; Stuss, Alexander, \& Benson, 1997).

Even though other deficiencies, such as an impairment in affective evaluation (Bechara, Damasio, Tranel, \& Damasio, 1997; Damasio, 1995, 1997; Mesulam, 1998) and the failure to energize oneself to form a goal commitment (Al-Adawi, Powell, \& Greenwood, 1998), may contribute to poor deliberation in patients with frontal brain lesions, insufficient cognitive weighing of the decision alternatives at hand may be most detrimental. As Knight, Grabowecky, and Scabini (1995) have pointed out, the capability to generate and evaluate counterfactuals is strongly hampered in patients with frontal lobe lesions. Accordingly, patients with frontal brain lesions in our study failed to become more intensively involved with weighing pros and cons in relation to an increase in perceived difficulty of the decision problem at hand. Our data thus confirm that lesions in areas of the frontal lobes lead to defective deliberation. Reflective action control in the sense of effortful goal selection seems to rely on processes that are subsumed in the frontal lobes' executive functions of control.

\section{Study 2: Reflexive Action Control}

Gollwitzer $(1993,1999)$ described how people can automatize the initiation of goal-directed actions by forming implementation intentions. Automatic action initiation is commonly found with habitual behaviors in which the same behavior has repeatedly and consistently been performed in the very same situation. Forming implementation intentions shortcuts this learning process (Gollwitzer \& Brandstäter. 1997: Gollwitzer \& Schaal, 1998) by simply linking critical anticipated situational cues to the intended goal-directed behavior ("If situation $y$ arises, I will perform the goal-directed behavior $z$ "). By forming a decisive plan ahead of time, action control becomes reflexive and does not require conscious deliberation once the critical situation is encountered.

Because patients with frontal brain lesions are easily distracted by environmental cues that trigger the execution of routine behaviors (Karnath et al., 1991), they should benefit from having formed implementation intentions. Furthermore, not only do frontal lobe lesions seem to spare the automatic initiation of behavior, but new habits can still be established through classical conditioning procedures (e.g., Daum, Channon, Polkey, \& Gray, 1991; Doyon et al., 1998) as long as the task does not require deliberative thinking or decision making (B. Levine, Stuss, \& Milberg, 1997; Petrides, 1997). Thus, when patients with frontal lobe lesions are helped to form implementation intentions, the positive consequences in terms of automatic action initiation should prevail. In other words, implementation intentions once formed should effectively control their behavior.

We used a dual-task paradigm that allowed us to assess the immediacy and efficiency of action initiation-two vital features of the automatic, reflexive control of action (Bargh, 1997). Immediacy was tested in a Go-NoGo task by measuring the speed of a button-press response. To assess efficiency, we manipulated the difficulty of the primary task (a motor tracking task), which also allowed us to observe the speed of responses under low versus high mental load conditions.

We predicted that when implementation intentions are formed, the initiation of the intended response should be facilitated in all groups of participants (patients with frontal lobe lesions, patients with nonfrontal lobe lesions, and university students) to the same degree. Moreover, we expected this effect to be independent of the difficulty of the competing task. According to classic findings from dual-task research (Heuer, 1996), there should be less interference between the button-press responses in the Go-NoGo task and the competing tracking task if the button-press responses are automatically controlled by implementation intentions.

\section{Method}

\section{Participants}

Of the 34 brain-injured participants, 20 had frontal lobe lesions ( 8 women, $12 \mathrm{men}$ ) and 14 had nonfrontal lobe lesions ( 8 
women, 6 men). The mean age in the FL group was 31.30 years $(S D=8.45)$, whereas in the NFL group, the mean age was 41.21 years $(S D=14.13)$. For the nonclinical control group (CFL and CNFL), 33 (16 female and 17 male) university students (mean age $=24.85$ years, $S D=3.15$ ) were randomly selected from the Max-Planck-Institute's pool of research participants.

In the FL group, lesions were due to head injury $(n=15)$ or to cerebrovascular disease $(n=5)$. Head injury $(n=4)$, cerebrovascular disease $(n=7)$, hypoxia $(n=1)$, and encephalitis $(n=2)$ were considered to be responsible for lesions in the NFL group (see Appendix $\mathrm{C}$ for single case information). Again, clinical data about lesion location, etiology, handedness, symptoms of paralysis, and different measures of cognitive functioning were available through the hospital's files. Patients were selected on the criteria that eye fixation and the movement of one arm as well as the respective hand were unimpaired; the foveal visual field contained an angle of at least $8^{\circ}$. Furthermore, patients had to have no visual neglect and had to display intact understanding of the instructions. The sample contained no acute cases; 3 I patients were in a chronic condition.

\section{Procedures, Equipment, and Materials}

We developed a dual task that allowed for interference and transfer. In dual-task research, interference is thought to depend on the nature of the tasks involved and on the extent to which the two tasks rely on the same resources. Transfer, in contrast, occurs when automatic control of performance in one task frees resources that can then be used to improve performance in the other task (Heuer, 1996; Heuer \& Schmidtke, 1996). Therefore, we used structurally similar tasks that used the same input channel (visual perception) and the same output channel (motor reaction). Task difficulty was varied systematically by increasing difficulty in the primary task. Furthermore, participants were forced to work on both tasks simultaneously. For this purpose, we used the same target for both tasks. This precaution was taken because we wanted to control for possible deficits in sustained attention (Rueckert \& Grafman, 1996) and to respect the fact that the ability of patients with frontal brain lesions to perform parallel tasks is still a controversial issue (Alderman, 1996; Baddeley, Della-Sala, Papagno, \& Spinnler, 1997; Vilkki, Virtanen, Surma-Aho, \& Servo, 1996):

Participants had to perform a dual task that combined a primary task of tracking with a secondary Go-NoGo task. The dual task was presented on a computer screen. A headrest was used to keep a distance of $50 \mathrm{~cm}$ between the participants' eyes and the screen. The target stimulus of both tasks-a circle $1.7 \mathrm{~cm}$ in diameter, corresponding with the foveal visual angle of $1-2^{\circ}$, thus providing maximal visual acuity (Nelson \& Loftus, 1980)-moved with a speed of $3 \mathrm{~cm} / \mathrm{s}$ within a delineated area $\left(18 \times 24.5 \mathrm{~cm}^{2}\right)$ on the screen in randomly designed curves.

Cover story. The purpose of the study was said to be to analyze the speed of encoding of information depicted on traffic signs. The experimenter was allegedly interested in how fast people process the number " 3 " under distracting circumstances.

Manipulation of task difficulty. The tracking task demanded continuous attention and was thus described to the participants as the primary task. The participants had to enclose the wandering circle in a square (tracking field) that could be moved by performing the equivalent movement with the mouse on a $52 \times 65-\mathrm{cm}^{2}$ mouse pad. Before each trial (to be explained below), the mouse had to be returned to a starting line. To vary the difficulty of the primary task, the size of the tracking field was set either to $4 \times 4$ $\mathrm{cm}^{2}$ (low difficulty) or to $2.2 \times 2.2 \mathrm{~cm}^{2}$ (high difficulty). Both of these squares are placed within the visual angle of $4-6^{\circ}$ (i.e., the area of parafoveal perception, according to Nelson \& Loftus,
1980). The dependent variable in the tracking task was percentage of overlap between square and circle. It was measured at discrete $1-s$ intervals and additionally whenever the mouse button was pressed (see below).

Manipulation of implementation intentions. The Go-NoGo task demanded only temporary attention and was thus described to the participants as the secondary task. Participants were asked to press the mouse button immediately if a number appeared in the circle and to forego pressing if a letter appeared (Go-NoGo paradigm). Participants were told to respond quickly and accurately. They were instructed to press the mouse button particularly fast if the number " 3 " appeared. This way, we established critical targets (i.e., the number " 3 "), noncritical targets (i.e., the numbers "1", "5," "7," "9"), and distractor targets (i.e., the letters $a, e, n, v$, $x$ ). All targets appeared three times per phase and were presented for $1 \mathrm{~s}$ in varying intervals $(2-7 \mathrm{~s})$ in fixed prerandomized order (each phase consisted of three randomized sequences containing the set of targets). Dependent variables were speed of button-press responses (accuracy in the range of $10 \mathrm{~ms}$ ) and correctness of these responses.

Two different instructions were given to all participants to create implementation intention trials versus control trials; the order of instructions was varied. Both instructions informed participants that they could accelerate their button-press responses to the number " 3 " by applying certain mental strategies. The implementation intention strategy implied the following mental exercise while looking at the number " 3 " presented on a card: "Start with the mental exercise now. Tell yourself: If the number ' 3 ' appears, I will press the button particularly fast! Tell yourself this sentence silently a couple of times, thus fully committing yourself to this plan." For the familiarization strategy (control instructions), participants received a sheet of paper carrying several lines of the number " 3 ." At various places, the number " 3 " was missing, and participants were asked to fill in the missing " 3 "s in the gaps. The familiarization instruction was meant to control for both effects of priming the number " 3 " and effects of experimenter demand.

\section{Design}

The participants of the four groups (FL, NFL, CFL, CNFL) were assigned to two task conditions. In one task condition, participants began to work under implementation intention instructions followed by familiarization instructions (Condition I-F). In the other task condition, participants began to work on the dual task under familiarization instructions followed by implementation intention instructions (Condition F-I). The two lesion groups in the two task conditions were balanced for gender, age, handedness, IQ, problem solving, Wisconsin Card Sorting Test (Grant \& Berg, 1993), and TOH scores. The student control groups (CFL, CNFL) matched the clinical groups with respect to gender.

Three blocks of trials were presented. The first block consisted of practice trials in which the Go-NoGo task and the tracking task had to be performed separately and in combination at both levels of difficulty. The second block contained four phases of dual-task performance. Each phase represented a different level of difficulty in an easy-difficult-difficult-easy (E-D-D-E) order (each phase lasted $150 \mathrm{~s}$ ). The second block of trials had to be performed either under implementation intention instructions or familiarization instructions. The third block again presented four phases of dual-task performance in an E-D-D-E order. All participants were told that they should now use a new strategy to speed up their responses to the number "3." Thus, when the second block was performed under familiarization instructions, the third block of trials was performed under implementation intention instructions, and vice versa. 
The design used in this study was a mixed-factorial design that consisted of two between factors and four within factors. The between factors were group (FL, NFL, CFL, CNFL) and order of instructions (F-I, I-F). The within factors were type of instructions (F, I), response type (critical: "3," noncritical: "1," "5," "7," "9"), difficulty of tracking task (E, D), and phases (E-D-D-E). As dependent variables, we used participants' speed of button-press response in the discrimination task and the percentage of overlap in the tracking task.

\section{Results}

\section{Performance on the Go-NoGo Task (Secondary Task)}

Overall response times. The speed of button-press responses of the FL group $(M=0.68 \mathrm{~s}, S D=0.11)$ and the NFL group $(M=0.67 \mathrm{~s}, S D=0.10)$ did not differ, $t(32)=0.26, n s$. The mean response times were faster in the student control group $(M=0.52 \mathrm{~s}, S D=0.05)$ than in the patient group $(M=0.67 \mathrm{~s}, S D=0.10), t(46)=8.10, p<$ .001 . Again, this difference is not surprising because the patient group was significantly older than the student group and may have included patients with slowed information processing.

Accuracy of discrimination. We used Rae's (1976) discrimination index $A^{\prime}$, ranging from 0 to 1.00 (from random to accurate discrimination), to compare the hit rate and the false-alarm rate. The discrimination index was close to 1.00 in all groups $\left(A_{\mathrm{FL}}^{\prime}=.97 ; A_{\mathrm{NFL}}^{\prime}=.97 ; A_{\mathrm{CFL}}^{\prime}=.99 ;\right.$ $\left.A^{\prime}{ }_{\mathrm{CNFL}}=.99\right)$; thus discrimination can be considered to be very accurate in all groups.

Speed-up effects with respect to the critical number " 3 ." To assess the strength of the speed-up effects, we computed difference scores (mean response time of the 12 noncritical responses minus mean response time of the 3 critical responses per phase) because such scores control for interindividual variance (e.g., information-processing speed). Positive scores point to a faster response to the critical number " 3 " as compared with the noncritical numbers.
A 2 (group: FL vs. NFL) $\times 2$ (instruction: $F$ vs. I) ANOVA comparing the FL group to the NFL group (see Table 3 ) yielded no effect of group, $F(1,32)=0.08$, $n s$; the expected effect of instruction, $F(1,32)=6.12, p<.05$; and no significant interaction effect, $F(1,32)=0.44$, ns. This suggests that for both patient groups, the implementation intention strategy produced a stronger speed-up effect than the familiarization strategy.

When comparing the group of all patients with brain lesions (BL) with the student group (STU) by a 2 (group: $\mathrm{BL}$ vs. STU) $\times 2$ (instruction: $F$ vs. I) ANOVA, an analogous pattern of data emerged (see Table 3 ). No effect of group was observed, $F(1,65)=0.04$, ns, but a significant instruction effect was found, $F(1,65)=10.22, p<.01$. The interaction effect of the two factors did not reach significance, $F(1,65)=1.76, n s$. It can be concluded that patients with brain lesions benefited as much from forming implementation intentions as university students.

The same pattern of data emerged when the FL group and the NFL group were compared separately with the respective student control groups. The main effects of group did not reach significance ( $p s>.45$ ), whereas the instruction effects were significant or marginally significant $\left(F_{\mathrm{FL}}\right.$ vs. CFL: $p<.01 ; F_{\mathrm{NFL}}$ vs. CNFL $: p<.08$ ); in both analyses, the instruction effect was not qualified by an interaction effect with the group factor $(p s>.45)$.

Finally, we observed no significant differences in single between-group contrasts when comparing the speed-up effects of familiarization instructions or implementation intention instructions separately (BL vs. STU, FL vs. NFL, FL vs. CFL, NFL vs. CNFL; all ts $<1.21, n s$ ).

We wondered whether the stronger speed-up effect of the implementation intention instructions as compared with the familiarization instructions may have simply been due to differentially slower responding to noncritical numbers under implementation intention instructions. However, the mean response times to noncritical numbers under implementation intention instructions and the mean response

Table 3

Mean Response Acceleration as a Function of Type of Instruction for the

Different Experimental Groups

\begin{tabular}{lllllll}
\hline \multicolumn{1}{c}{ Type of instruction } & FL & NFL & CFL & CNFL & BL & STU \\
\hline Implementation intention & $0.10_{\mathrm{a}}^{*}$ & $0.11_{\mathrm{a}}$ & $0.08_{\mathrm{a}}^{*}$ & $0.09_{\mathrm{a}}^{*}$ & $0.10_{\mathrm{a}}^{*}$ & $0.08_{\mathrm{a}}^{*}$ \\
$M$ & 0.06 & 0.09 & 0.04 & 0.06 & 0.07 & 0.05 \\
$S D$ & $0.06_{\mathrm{b}}$ & $0.04_{\mathrm{b}}$ & $0.06_{\mathrm{b}}$ & $0.07_{\mathrm{b}}$ & $0.05_{\mathrm{b}}$ & $0.06_{\mathrm{b}}$ \\
$\begin{array}{l}\text { Familiarization } \\
M\end{array}$ & 0.08 & 0.12 & 0.03 & 0.06 & 0.09 & 0.04 \\
$S D$ &
\end{tabular}

Note. All values are difference scores (noncritical minus critical targets) in seconds. Means in the same row that share a common subscript do not differ significantly in planned single contrasts ( $t$ tests comparing FL vs. NFL, FL vs. CFL, NFL vs. CNFL, CFL vs. CNFL). FL = patients with frontal lobe lesion $(n=20)$; NFL $=$ patients with nonfrontal lobe lesion $(n=14) ; \mathrm{CFL}=$ student control group for FL $(n=20) ; \mathrm{CNFL}=$ student control group for NFL $(n=14) ; \mathrm{BL}=$ patients with brain lesions (FL and NFL; $n=34$ ); STU = student control group for BL (CFL and CNFL; $n=33$ ). * Indicates a significant within-comparison of implementation intention instructions versus familiarization instructions, $p<.05$. 
times to noncritical numbers under familiarization instructions did not differ: STU, $t(32)=1.57, n s ; \mathrm{BL}, t(33)$ $=0.39, n s$. Therefore, the stronger speed-up effects in responding to the critical numbers under implementation intention instructions cannot be attributed to less effective responding to the noncritical numbers.

Order effects of instructions. Correlations between the order of instructions $(1=$ Condition I-F, $2=$ Condition $\mathrm{F}-\mathrm{I})$ and the difference scores of responding to noncritical versus critical numbers were computed to assess whether the implementation intention instructions would produce stronger effects when they were given first or second. However, the order of instructions was not critical for the difference scores under implementation intention instructions $\left(r_{\mathrm{STU}}=-.14, n s ; r_{\mathrm{BL}}=-.12, n s\right)$. It can be concluded, therefore, that implementation intentions produced their ef fects no matter whether they were given prior to or after the familiarization instructions.

\section{Performance on the Tracking Task (Primary Task)}

As expected, an increase in task difficulty led to a significant decrease in average tracking performance. The average overlap of mouse field and target field in difficult phases of tracking $\left(M_{\mathrm{STU}}=82 \%, S D=4.59 ; M_{\mathrm{BL}}=53 \%\right.$, $S D=13.78)$ was significantly lower than in easy phases of tracking $\left(M_{\mathrm{STU}}=97 \%, S D=1.04 ; M_{\mathrm{BL}}=82 \%\right.$, $S D=10.77):$ STU, $t(32)=25.84, p<.001 ; \mathrm{BL}$ $t(33)=28.46, p<.001$.

The performance measures in the tracking task could have been affected by the use of the dominant or the nondominant hand. However, we found no significant correlation between the hand used (nondominant $=0$ and dominant $=1)$ and the amount of overlap $(r=.25)$.

\section{Interference Between Primary and Secondary Task Performance}

General effects of the secondary task on the primary task. We analyzed whether the two different instructions ( $F$ vs. 1 ) on how to perform the Go-NoGo task would affect overall tracking performance. The percentage of average overlap achieved in the tracking task was the same under both types of instructions (all $t \mathrm{~s}<1.71, n s$ ), indicating that implementation intentions' stronger speed-up effects in the Go-NoGo task are neither produced at the cost of shifting attention away from the tracking task nor a result of a general rise in vigilance.

Specific effects of the secondary task on the primary task. The assumption that implementation intentions automatize action initiation implies that this process demands little capacity and that free capacities can be transferred to the parallel task. Whenever participants perform a critical response under implementation intention instructions, tracking performance should be better as compared with familiarization instructions, particularly when the mental load is high (difficult tracking performance). Accordingly, we analyzed participants' tracking performance in the difficult tracking phases exactly at those points in time when critical responses were performed in the secondary task. We predicted better tracking performances in the difficult tracking phases when participants operated under implementation intention instructions as compared with familiarization instructions. Indeed, we observed the expected differences whenever critical responses were performed in phases of difficult tracking with lesion patients $\left(M_{1}=63 \%\right.$, $\left.S D=16.58 ; M_{\mathrm{F}}=55 \%, S D=19.15\right), t(33)=2.21, p<$ .05 , but not with university students $\left(M_{\mathrm{I}}=85 \%, S D=8.58\right.$; $\left.M_{\mathrm{F}}=83 \%, S D=11.66\right), t(32)=0.51, n s$. Because the tracking task was easier for university students—producing less mental load than in the patient group-it makes sense that their tracking performance benefited less from the automatic action initiation in the secondary task. Finally, we observed that when noncritical responses had to be performed, no differences occurred between tracking performances under implementation intention instructions as compared with familiarization instructions for lesion patients and university students (all $t \mathrm{~s}<0.67$, all $p \mathrm{~s}>.51$ ).

Effects of the primary task on the secondary task. To make sure that the interference intended by the dual-task paradigm had actually taken place, critical and noncritical responses (see Figure 1) were analyzed separately for familiarization instructions and implementation intention instructions in four 2 (group: BL vs. STU) $\times 4$ (phase: Phase 1 to Phase 4) ANOVAs, including trend analyses for the within-factor phase (note that the E-D-D-E order of tracking phases would lead one to expect a quadratic trend rather than a linear or other trend). Slowing effects in phases of difficult tracking as compared with phases of easy tracking were observed for critical and noncritical responses under familiarization instructions as well as for critical responses under implementation intention instructions $\left(F_{\text {quad }} s>5.30, p \mathrm{~s}<.05\right.$, accounting for $8-15 \%$ of variance). There were significant group differences in overall response times $\left(F_{\mathrm{S}}>54.37, p \mathrm{~s}<.001\right)$, but no interaction effects $\left(F_{\text {linear, quad }}<0.71, n s\right)$.

For noncritical responses under implementation intention instructions, we observed with all groups of participants a linear improvement over time, $F_{\text {linear }}(1,65)=15.02, p<$ $.001, \eta^{2}=.19$. Because this effect was stronger in the patient group, $F_{\text {linear }}(1,33)=10.35, p<.01, \eta^{2}=.24$, than in the student group, $F_{\text {linear }}(1,32)=7.46, p<.01, \eta^{2}=$ .19 , a significant interaction effect was observed, $F_{\text {linear }}(1$, $65)=4.61, p<.05, \eta^{2}=.07$.

Even though we found task interference (of the tracking task on the Go-NoGo task) in the form of a slowing of critical responses after both kinds of instructions and a slowing of noncritical responses after familiarization instructions in phases of difficult tracking, we observed that under implementation intention instructions, noncritical responses were not affected by the difficulty of the tracking task. The initiation of the critical responses under implementation intention instructions apparently frees cognitive capacities that can be used not only for performing the tracking task (see above) but also for responding to the noncritical numbers. This present pattern of data strongly speaks for efficient action initiation by implementation intentions. 


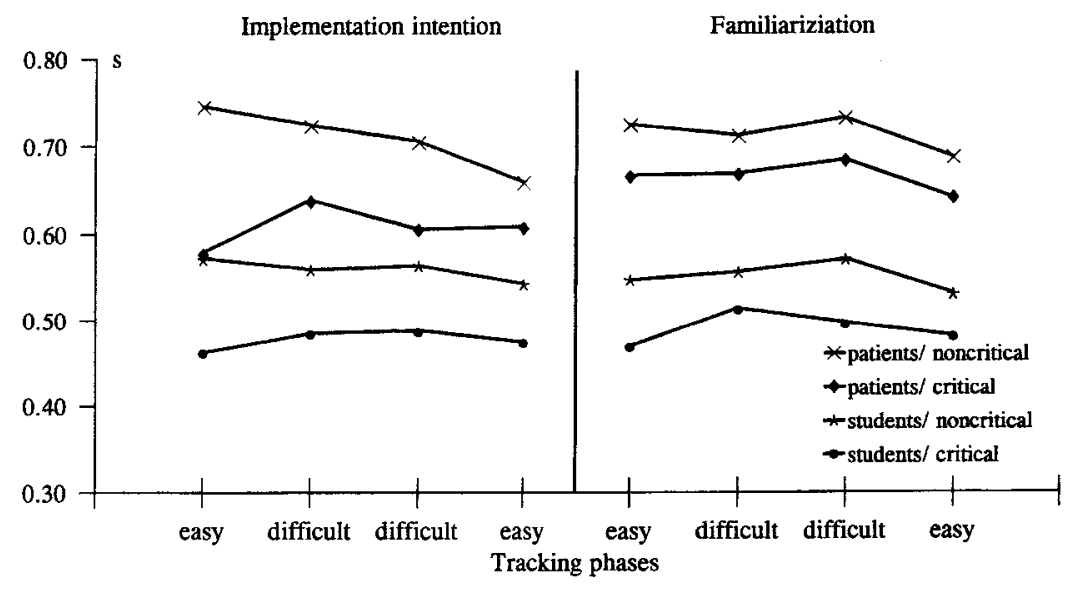

Figure 1. Mean response times of patients and students for noncritical and critical targets in phases of easy and difficult tracking under implementation intention instructions versus familiarization instructions.

Effects of the primary task on the speed-up effect in the secondary task. The assumption of the automatization of action initiation through implementation intentions implies that the speed-up effects produced by implementation intentions should show up in the easy and difficult tracking phases alike. When we subjected the difference scores under implementation intention instructions (mean speed of the 12 noncritical responses minus mean speed of the 3 critical responses per phase) to a 2 (group: BL vs. STU) $\times 2$ (tracking phase: E vs. D) ANOVA, no significant main effects for either group or difficulty were observed (E: $M_{\mathrm{BL}}=0.11 \mathrm{~s}, S D=0.11, M_{\mathrm{STU}}=0.09 \mathrm{~s}, S D=0.05 ; \mathrm{D}$ : $M_{\mathrm{BL}}=0.09 \mathrm{~s}, S D=0.07, M_{\mathrm{STU}}=0.08 \mathrm{~s}, S D=0.06$; $F \mathrm{~s}<1.74, n s)$, nor was an interaction effect found, $F(1$, $65)=0.04, n s$. In all groups, the speed-up effects achieved through implementation intentions seem to rely on cognitive processes that do not require much cognitive capacity.

\section{Grouping Lesion Patients by Their TOH Performance}

In a further step, we wanted to explore the functional distinction of conscious deliberative action control and ac- tion control through implementation intentions in more detail by analyzing whether patients with impaired conscious deliberation as measured by the TOH would be able to speed up their responses using implementation intentions. Processes of deliberative planning may facilitate quick responding to critical numbers under familiarization instructions. However, because the speed-up effects under implementation intention instructions are primarily based on automatic processes, any attempts to increase performance by conscious planning should only hinder these processes to run off smoothly.

As in Study 1, we conducted ANOVAs that split lesion patients into weak and strong performers on the TOH. In a 2 (type of instruction: F vs. I) $\times 2$ (performance on the TOH: weak vs. strong) ANOVA, no significant main effect for performance on the TOH, $F(1,28)=0.04$, ns, was observed. The known significant effect for instruction, $F(1$, $28)=8.83, p<.01$, was qualified by an interaction with the TOH performance, $F(1,28)=4.90, p<.05$. This pattern of data (see Table 4) suggests that the speed-up effects of implementation intentions are particularly pronounced when there is little potential for deliberative planning,

Table 4

Mean Response Acceleration as a Function of Performance on the Tower of Hanoi (TOH) and Type of Instruction

\begin{tabular}{|c|c|c|c|c|c|c|c|c|}
\hline \multirow[b]{3}{*}{ Type of instruction } & \multicolumn{4}{|c|}{ Lesion patients } & \multicolumn{4}{|c|}{ Students } \\
\hline & \multicolumn{2}{|c|}{$\begin{array}{l}\text { Weak TOH } \\
\text { performance }^{\mathrm{a}}\end{array}$} & \multicolumn{2}{|c|}{$\begin{array}{c}\text { Strong TOH } \\
\text { performance }\end{array}$} & \multicolumn{2}{|c|}{$\begin{array}{l}\text { Weak TOH } \\
\text { performance }^{\text {a }}\end{array}$} & \multicolumn{2}{|c|}{$\begin{array}{c}\text { Strong } \mathrm{TOH} \\
\text { performance }\end{array}$} \\
\hline & $M$ & $S D$ & $M$ & $S D$ & $M$ & $\overline{S D}$ & $M$ & $S D$ \\
\hline Implementation intention & $.14_{\mathrm{a}}^{*}$ & .08 & $.09_{\mathrm{b}}$ & .05 & $.09_{\mathrm{c}}^{*}$ & .03 & $.09_{\mathrm{b} . \mathrm{c}}^{*}$ & .05 \\
\hline Familiarization & $.03_{\mathrm{a}}$ & .10 & $.07 \mathrm{a}$ & .07 & $.07_{\mathrm{a}}$ & .03 & $.06_{\mathrm{a}}$ & .06 \\
\hline \multicolumn{9}{|c|}{$\begin{array}{l}\text { Note. All values are difference scores (noncritical minus critical targets) in seconds. Means in the } \\
\text { same row that do not share a common subscript differ at } p<.05 \text { in planned single contrasts }(t \text { tests). } \\
\text { The participants of the student control group were randomly assigned to the weak versus strong } \\
\text { TOH control groups. } \\
\text { a } n=14 \text {. b } n=16 \text {. } \\
* \text { Indicates a significant within-comparison of implementation intention instructions versus famil- }\end{array}$} \\
\hline
\end{tabular}


whereas the reverse is true for the speed-up effects achieved under familiarization instructions.

Additionally, a random student sample of the respective size $(n=16$; see Table 4$)$ was taken and compared with patients who had a strong performance on the TOH. The respective 2 (type of instruction: $\mathrm{F}$ vs. I) $\times 2$ (group: patients vs. students) ANOVA revealed no group main effect, $F(1,30)=0.18, n s$; the expected effect of instruction, $F(1,30)=4.18, p<.05$; and no significant interaction effect, $F(1,30)=0.27, n s$, indicating that patients with a strong performance on the TOH task showed the same pattern of data as university students. A final 2 (type of instruction: $F$ vs. I) $\times 2$ (group: patients vs. students) ANOVA comparing the patients performing weakly on the TOH task to a second randomly selected student sample $(n=14$; see Table 4$)$ yielded no effect of group, $F(1$, $26)=0.14, n s$; a significant effect of instruction, $F(1$, 26) $=10.40, p<.01$; and a significant interaction effect, $F(1,26)=4.23, p<.05$. It appears, then, that lesion patients with weak performances on the TOH task benefit more from the implementation intention instructions than either the university students or those patients with strong performances on the $\mathrm{TOH}$.

\section{Discussion}

Although patients with frontal and nonfrontal brain lesions responded slower to the target stimuli than university students, all participants managed to speed up their responses to critical stimuli as compared with noncritical stimuli more by forming implementation intentions than by using the familiarization strategy. Forming implementation intentions had no effect on attention or effort in general but enhanced performance selectively whenever the critical situational cue was encountered. These effects of implementation intentions cannot be explained in terms of experimenter demand because participants showed positive difference scores (i.e., faster critical than noncritical responses) under both implementation intention instructions and familiarization instructions.

When participants were encouraged to form implementation intentions, the speed-up effect in the group of patients with frontal lobe lesions was at least as strong as in all of the other groups. Apparently, the notorious stimulus dependence of patients with frontal brain lesions (Lhermitte, 1983) appears to be of good use when it comes to quickly initiating responses to anticipated stimuli. When taking the lesion patients' performance on the TOH task into account, we found that patients with defective deliberation (i.e., a weak performance on the TOH) performed better under implementation intention instructions than patients with intact deliberation (i.e., a strong performance on the $\mathrm{TOH}$ ) or even university students. Moreover, lesion patients with weak TOH performance did not show an acceleration of button pressing under familiarization instructions. The latter observation suggests that under familiarization instructions, participants had to deliberately and reflectively build and use strategies on their own-a function known to be impaired in cases of frontal lobe lesions (Burgess \& Shallice, 1996).

The observation that the effect of implementation intentions is reduced in university students and lesion patients who are able to exert conscious behavioral control (i.e., strong TOH performance) suggests that normal brain functioning provides a kind of continuous conscious metacontrol that may, at times, interfere with automatic processes. $\mathrm{Ob}$ viously, the inability to exert conscious control is advantageous in tasks of reflexive action initiation, because conscious processing to deliberately control automatic processes decreases accuracy and slows performance (Delacour, 1995; Norman \& Shallice, 1986).

Two features of automatic processes are immediacy and efficiency (Bargh, 1997; Logan, 1992). With respect to immediacy, implementation intentions helped to speed up critical button-press responses. With respect to efficiency, implementation intentions reduced mental load during task performance in two ways: First, tracking performance was improved whenever a critical button-press response was performed in phases of difficult tracking, and second, effects of practice were achieved over the four phases with respect to noncritical responses. These findings provide further evidence that implementation intentions create automatic action control and can therefore be considered as a shortcut to establishing automatic responses that otherwise require extensive training. Once formed, implementation intentions seem to produce their effect on behavior independent of conscious control processes and independent of intact frontal lobe functioning.

\section{General Discussion}

Only some aspects of planning and action control seem to depend on intact frontal lobe functioning. There is no doubt of frontal lobe participation in those aspects of action control that relate to deliberating decisions. However, other aspects of action control-namely, the automatic control of intended behavior-seem independent of frontal lobe functions.

In our two experiments, two entirely different kinds of mental processes in action control (Gollwitzer, 1999) were tested. In Study 1, we focused on conscious deliberation and therefore on aspects of reflective action control, whereas in Study 2, we tried to assess processes of automatic action initiation and thus reflexive processes of action control. In patients with various frontal lesions (see Appendixes A and C), reflective action control (in terms of choosing between action goals) was found to be severely hampered, whereas reflexive action control processes (i.e., action control guided by implementation intentions) were intact.

The quality of mental processing in the experimental tasks was, in both studies, compared with the performance on the TOH task, as this task does (at an early stage of task performance) assess conscious deliberation. Splitting the patient groups according to their performance on the TOH 
task produced inspiring results that are all the more important because some patients from the nonfrontal lobe group had lesions in brain areas that are considered to play a part in the dorsolateral prefrontal-subcortical circuit that provides reciprocal connections between the dorsolateral prefrontal cortex, the "dorsolateral portion of the caudate nucleus, distinct areas of the globus pallidus and substantia nigra, and ventral anterior and medial nuclei of the thalamus" (Cummings, 1995, p. 2), and is claimed to be involved in executive functions.

In Study 1, patients with difficulties solving the TOH task showed inadequate relations of perceived difficulty and rated certainty to decision times, whereas patients with intact deliberative planning (i.e., a strong performance on the $\mathrm{TOH}$ ) showed a pattern similar to the student control group. However, in Study 2, patients with weak TOH performances achieved stronger speed-up effects than both patients with strong performances and university students. We conclude that the cognitive processes underlying implementation intentions and those underlying performances on the TOH task must be contrary in nature.

Deliberation depends on reflective conscious processes that are involved in working memory (Baddeley, 1986; Goldman-Rakic, 1993) and related to frontal lobe functioning (Carter et al., 1998; Saint-Cyr, Taylor, Trépanier, \& Lang, 1992). However, patients with frontal lesions are still capable of reflexive action control. Their behavior can become stimulus bound and inflexible because of an inability to perform acts of mental stimulation and reality checking (Knight et al., 1995). Accordingly, the results of both of our studies taken together suggest that the inability to deliberate decision outcomes is complemented with an extreme stimulus dependence that helps to reap the benefits of implementation intentions. This pattern of dissociation was also observed with the only frontal lesion patient who, per chance, participated in both studies. This patient performed weakly on the TOH, showed an impairment in reflective deliberation (Study 1), but successfully managed to speed up critical responses under implementation intention instructions (Study 2). Although the two studies presented do not allow us to determine a double dissociation of brain areas, we still observed a double dissociation of brain functioning.

From our data, we can determine neither which parts of the frontal lobes are particularly related to deliberation nor which parts of the nonfrontal brain are related to action control on the basis of implementation intentions. However, in post hoc analyses, we focused on the performance of those patients with frontal brain lesions who had lesions in the dorsolateral frontal lobes, which are considered to be central for processes related to executive functioning (Cummings, 1995; Petrides, 1995; Stuss \& Benson, 1986). Study 1 contained 7 patients with dorsolateral frontal lobe damage (see Appendix A). According to the argument developed above, they should show deficits in deliberation Indeed, all of them showed weak positive correlations between problem difficulty and decision time as well as weak negative correlations between rated decision certainty and decision time. In Study 2, 4 of the 5 patients with dorsolat- eral frontal lesions (see Appendix C) could improve their performance under implementation intention instructions as compared with familiarization instructions, whereas the 5 th patient, who had additional damage to areas in the parietal cortex, was unable to speed up his responses. Again, these observations would support the above cited notion that dorsolateral frontal functioning is essential in conscious processes of action control but is not a necessary component of action initiation through implementation intentions.

Our data cannot resolve the issue of the location or pathways of the functional systems in the brain that are responsible for the effects of implementation intentions. To answer this question, neuroimaging studies with healthy volunteers need to be conducted as well as lesion studies that focus exactly on those parts of the brain known to be related to automatic behaviors. The basal ganglia, especially the striatum and the head of the nucleus caudatus, seem to be involved with the execution of routine behavioral programs (Knopman \& Nissen, 1991; Partiot et al., 1996) and with associative habit learning (Knowlton, Mangels, \& Squire, 1996). Moreover, cerebellar functions are basic features of classical conditioning (Daum et al., 1993), and in parietal brain areas, sensoric input and automatic output are thought to be closely related (Brody \& Pribram, 1978; Snyder, Batista, \& Andersen, 1997).

Finally, our findings have important implications for rehabilitation and therapy in patients with frontal lobe lesions. Commonly, new routines are developed in patients with frontal lobe lesions through extensive practice (SchmitterEdgecombe \& Rogers, 1997). According to the results of our second study, such routines could also be established simply by forming implementation intentions. This way of shortcutting the otherwise lengthy process of habit formation is an economical and very effective self-regulatory tool for organizing one's everyday conduct (Gollwitzer, 1999). Therefore, next to classic instruments of behavior therapy (e.g., Becker \& Vakil, 1993; Hux, Reid, \& Lugert, 1994; Sohlberg, Mateer, \& Stuss, 1993), the strategy of forming implementation intentions could be offered to patients with frontal brain lesions to help them organize their daily activities.

\section{References}

Al-Adawi, S., Powell, J. H., \& Greenwood, R. J. (1998). Motivational deficits after brain injury: A neuropsychological approach using new assessment techniques. Neuropsychology, 12, 115124.

Alderman, N. (1996). Central executive deficit and response to operant conditioning methods. Neuropsychological Rehabilitation, 6, 161-186.

Baddeley, A. (1986). Working memory. Oxford, England: Oxford University Press.

Baddeley, A., Della-Sala, S., Papagno, C., \& Spinnler, H. (1997). Dual-task performance in dysexecutive and nondysexecutive patients with a frontal lesion. Neuropsychology, 11, 187-194.

Bargh, J. A. (1997). The automaticity of everyday life. In R. S. Wyer (Ed.), Advances in social cognition (Vol. 10, pp. 1-48). Mahwah, NJ: Erlbaum. 
Bechara, A., Damasio, A. R., Damasio, H., \& Anderson, S. W. (1994). Insensitivity to future consequences following damage to human prefrontal cortex. Cognition, 50, 7-15.

Bechara, A., Damasio, H., Tranel, D., \& Damasio, A. R. (1997, February 28). Deciding advantageously before knowing the advantageous strategy. Science, 275, 1293-1295.

Beck, A. T., Rush, A. J., Shaw, B. F., \& Emery, G. (1986). Kognitive therapie der depression [Cognitive therapy of depression]. München, Germany: PVU/Urban und Schwarzenberg.

Beck, A. T., \& Steer, R. A. (1987). Beck Depression Inventorymanual. San Antonio, TX: Psychological Corporation.

Becker, M. E., \& Vakil, E. (1993). Behavioural psychotherapy of the frontal-lobe-injured patient in an outpatient setting. Brain Injury, 7, 515-523.

Brody, B. A., \& Pribram, K. H. (1978). The role of frontal and parietal cortex in cognitive processing. Tests of spatial and sequence functions. Brain, 101, 607-633.

Burgess, P. W., \& Shallice, T. (1996). Response suppression, initiation and strategy use following frontal lobe lesion. Neuropsychologia, 34, 263-273.

Carter, C. S., Braver, T. S., Barch, D. M., Botvinick, M. M., Noll, D., \& Cohen, J. D. (1998, May 1). Anterior cingulate cortex, error detection, and the online monitoring of performance. Science, 280, 747-749.

Cockburn, J. (1995). Task interruption in prospective memory: A frontal lobe function? Cortex, 31, 87-97.

Coolidge, F. L., \& Griego, J. A. (1995). Executive functions of the frontal lobes: Psychometric properties of a self-rating scale. Psychological Reports, 77, 24-26.

Cummings, J. L. (1995). Anatomic and behavioral aspects of frontal-subcortical circuits. In J. Grafman, K.-J. Holyoak, \& F. Boller (Eds.), Structure and functions of the human prefrontal cortex (pp. 1-13). New York: New York Academy of Sciences.

Damasio, A. R. (1985). The frontal lobes. In K. M. Heilmann \& E. Valenstein (Eds.), Clinical neuropsychology (pp. 339-375). New York: Oxford University Press.

Damasio, A. R. (1995). On some functions of the human prefrontal cortex. In J. Grafman, K.-J. Holyoak, \& F. Boller (Eds.), Structure and functions of the human prefrontal cortex (pp. 241251). New York: New York Academy of Sciences.

Damasio, A. R. (1997, April 24). Towards a neuropathology of emotion and mood. Nature, 386, 769-770.

Damasio, A. R., Tranel, D., \& Damasio, H. C. (1991). Somatic markers and the guidance of behavior: Theory and preliminary testing. In H. S. Levin, H. M. Eisenberg, \& A. L. Benton (Eds.), Frontal lobe function and dysfunction (pp. 218-229). New York: Oxford University Press.

Daum, I., Ackermann, H., Schugens, M. M., Reimold, C., Dichgans, J., \& Birbaumer, N. (1993). The cerebellum and cognitive functions in humans. Behavioral Neuroscience, 107, 411-419.

Daum, I., Channon, S., Polkey, C. E., \& Gray, J. A. (1991). Classical conditioning after temporal lobe lesions in man: Impairment in conditional discrimination. Behavioral Neuroscience, 105, 396-408.

Decary, A., \& Richer, F. (1995). Response selection deficits in frontal excisions. Neuropsychologia, 33, 1243-1253.

Delacour, J. (1995). An introduction to the biology of consciousness. Neuropsychologia, 33, 1061-1074.

Della Malva, C. L., Stuss, D. T., D'Alton, J., \& Willmer, J. (1993). Capture errors and sequencing after frontal brain lesions. Neuropsychologia, 31, 363-372.

Doyon, J., Laforce, R., Jr., Bouchard, G., Gaudreau, D., Roy, J., Poirier, M., Bédard, P. J., Bédard, F., \& Bouchard, J.-P. (1998). Role of the striatum, cerebellum and frontal lobes in the autom- atization of a repeated visuomotor sequence of movements. Neuropsychologia, 36, 625-641.

Eslinger, P. J., \& Damasio, A. R. (1985). Severe disturbance of higher cognition after bilateral frontal lobe ablation: Patient EVR. Neurology, 35, 1731-1741.

Fukui, T., Hasegawa, Y., Sugita, K., \& Tsukagoshi, H. (1993). Utilization behavior and concomitant motor neglect by bilateral frontal lobe damage. European Neurology, 33, 325-330.

Fuster, J. M. (1989). The prefrontal cortex. Anatomy, physiology and neuropsychology of the frontal lobe. New York: Raven Press.

Goel, V., \& Grafman, J. (1995). Are the frontal lobes implicated in "planning" functions? Interpreting data from the Tower of Hanoi. Neuropsychologia, 33, 623-642.

Goldman-Rakic, P. S. (1993). Specification of higher cortical functions. Journal of Head Trauma Rehabilitation, 8, 13-23.

Gollwitzer, P. M. (1990). Action phases and mind-sets. In E. T. Higgins \& R. M. Sorrentino (Eds.), Handbook of motivation and social cognition: Foundations of social behavior (Vol. 2, pp. 53-92). New York: Guilford Press.

Gollwitzer, P. M. (1993). Goal achievement: The role of intentions. In W. Stroebe \& M. Hewstone (Eds.), European review of social psychology (Vol. 4, pp. 141-185). London: Wiley.

Gollwitzer, P. M. (1999). Implementation intentions and effective goal pursuit: Strong effects of simple plans. American Psychologist, 54, 493-503.

Gollwitzer, P. M., \& Brandstätter, V. (1997). Implementation intentions and effective goal pursuit. Journal of Personality and Social Psychology, 73, 186-199.

Gollwitzer, P. M., \& Schaal, B. (1998). Metacognition in action: The importance of implementation intentions. Personality and Social Psychology Review, 2, 124-136.

Grant, D. A., \& Berg, E. A. (1993). Wisconsin Card Sorting Test (WCST). Göttingen, Germany: Hogrefe.

Grattan, L. M., \& Eslinger, P. J. (1991). Frontal lobe damage in children and adults: A comparative review. Developmental Neuropsychology, 7, 283-326.

Harlow, J. M. (1993). Recovery from the passage of an iron bar through the head. History of Psychiatry, 4, 271-281. (Original work published 1896)

Heckhausen, H. (1991). Motivation and volition. Heidelberg, Germany: Springer-Verlag.

Heckhausen, H., \& Gollwitzer, P. M. (1987). Thought contents and cognitive functioning in motivational versus volitional states of mind. Motivation and Emotion, 11, 101-120.

Heuer, H. (1996). Dual-task performance. In O. Neumann \& A. F. Sanders (Eds.), Handbook of perception and action, Vol. 3: Attention (pp. 113-153). London: Academic Press.

Heuer, H., \& Schmidtke, V. (1996). Secondary-task effects on sequence learning. Psychological Research, 59, 119-133.

Hux, K., Reid, R., \& Lugert, M. (1994). Self-instruction training following neurological injury. Applied Cognitive Psychology, 8 , 259-271.

Janowsky, J. S., Shimamura, A. P., \& Squire, L. R. (1989). Source memory impairment. Neuropsychologia, 27, 1043-1056.

Jeannerod, M. (1997). The cognitive neuroscience of action. Cambridge, MA: Blackwell Publishers.

Johnson, M. K., O'Connor, M., \& Cantor, J. (1997). Confabulation, memory deficits, and frontal dysfunction. Brain and Cognition, 34, 189-206.

Karnath, H.-O., Wallesch, C. W., \& Zimmermann, P. (1991). Mental planning and anticipatory processes with acute and 
chronic frontal lobe lesions: A comparison of maze performance in routine and non-routine situations. Neuropsychologia, 29, 271-290.

Knight, R. T., Grabowecky, M. F., \& Scabini, D. (1995). Role of human prefrontal cortex in attention control. In H. H. Jasper, S. Riggio, \& P. S. Goldman-Rakic (Eds.), Epilepsy and the functional anatomy of the frontal lobe (pp. 21-36). New York: Raven Press.

Knopman, D., \& Nissen, M. J. (1991). Procedural learning is impaired in Huntington's disease: Evidence from the serial reaction time task. Neuropsychologia, 29, 245-254.

Knowlton, B. J., Mangels, J. A., \& Squire, L. R. (1996, September 6). A neostriatal learning system in humans. Science, 273, $1399-1402$.

Konow, A., \& Pribram, K. H. (1970). Error recognition and utilization produced by injury to the frontal cortex in man. Neuropsychologia, 8, 489-491.

Kotovsky, K., Hayes, J. R., \& Simon, H. A. (1985). Why are some problems hard? Evidence from Tower of Hanoi. Cognitive Psychology, 17, 248-294.

Levin, H. S., Goldstein, F. C., Williams, D. H., \& Eisenberg, H. M. (1991). The contribution of frontal lobe lesions to the neurobehavioral outcome of closed head injury. In H. S. Levin, H. M. Eisenberg, \& A. L. Benton (Eds.), Frontal lobe function and dysfunction (pp. 318-338). New York: Oxford University Press.

Levine, B., Stuss, D. T., \& Milberg, W. P. (1997). Effects of aging on conditional associative learning: Process analyses and comparison with focal frontal lesions. Neuropsychology, 11, 367381 .

Levine, D. S., Leven, S. J., \& Prueitt, P. S. (1992). Integration, disintegration and the frontal lobes. In D. S. Levine \& S. J. Leven (Eds.), Motivation, emotion, and goal direction in neural networks (pp. 301-335). Hillsdale, NJ: Erlbaum.

Lhermitte, F. (1983). "Utilization behaviour" and its relation to lesions of the frontal lobes. Brain, 106, 237-255.

Lhermitte, F. (1986). Human autonomy and the frontal lobes. Part II: Patient behavior in complex and social situations: The "environmental dependency syndrome." Annals of Neurology, 19, 335-343.

Lhermitte, F., Pillon, B., \& Serdaru, M. (1986). Human autonomy and the frontal lobes. Part I: Imitation and utilization behavior: A neuropsychological study of 75 patients. Annals of Neurology, 19, 326-334.

Logan, G. D. (1992). Attention and preattention in theories of automaticity. The American Journal of Psychology, 105, 317 339.

Luria, A. R. (1962). Higher cortical functions in man. New York: Basic Books.

Luria, A. R. (1973). The frontal lobes and the regulation of behavior. In K. H. Pribram \& A. R. Luria (Eds.), Psychophysiology of the frontal lobes (pp. 3-26). New York: Academic Press.

Mann, L., \& Taylor, V. A. (1970). The effects of commitment and choice difficulty on predecision processes. The Journal of Social Psychology, 82, 221-230.

McAndrews, M. P., \& Milner, B. (1991). The frontal cortex and memory for temporal order. Neuropsychologia, 29, 849-859.

Mesulam, M.-M. (1998). From sensation to cognition. Brain, 121, 1013-1052.

Milner, B. (1963). Effects of different brain lesions on card sorting. Archives of Neurology, 9, 100-110.
Milner, B., Petrides, M., \& Smith, M. L. (1985). Frontal lobes and the temporal organization of memory. Human Neurobiology, 4 , 137-142.

Morris, R. G., Ahmed, S., Syed, G. M., \& Toone, B. K. (1993). Neural correlates of planning ability: Frontal lobe activation during the Tower of London test. Neuropsychologia, 31, 13671378 .

Nelson, W. W., \& Loftus, G. R. (1980). The functional visual field during picture viewing. Journal of Experimental Psychology: Human Learning and Memory, 6, 391-399.

Norman, D. A., \& Shallice, T. (1986). Attention to action. Willed and automatic control of behavior. In R. J. Davidson, G. E. Schwartz, \& D. Shapiro (Eds.), Consciousness and self-regulation. Advances in research and theory (Vol. 4, pp. 1-18). New York: Plenum Press.

Owen, A. M., Downes, J. J., Sahakian, B. J., Polkey, C. E., \& Robbins, T. W. (1990). Planning and spatial working memory following frontal lobe lesions in man. Neuropsychologia, 28, 1021-1034.

Owen, A. M., Doyon, J., Dagher, J., Sadikot, A., \& Evans, A. C. (1998). Abnormal basal ganglia outflow in Parkinson's disease identified with PET. Implications for higher cortical functions. Brain, 121, 949-965.

Partiot, A., Vérin, M., Pillon, B., Teixeira-Ferreira, C., Agid, Y., \& Dubois, B. (1996). Delayed response tasks in basal ganglia lesions in man: Further evidence for a striatofrontal cooperation in behavioural adaptation. Neuropsychologia, 34, 709-721.

Peterson, D. K., \& Pitz, G. F. (1988). Confidence, uncertainty, and the use of information. Journal of Experimental Psychology: Learning, Memory, and Cognition, 14, 85-92.

Petrides, M. (1995). Functional organization of the human frontal cortex for mnemonic processing. Evidence from neuroimaging studies. In J. Grafman, K.-J. Holyoak, \& F. Boller (Eds.), Structure and functions of the human prefrontal cortex (pp. 85-96). New York: New York Academy of Sciences.

Petrides, M. (1997). Visuo-motor conditional associative learning after frontal and temporal lesions in the human brain. Neuropsychologia, 35, 989-997.

Petrides, M., \& Milner, B. (1982). Deficits on subject-ordered tasks after frontal-and temporal-lobe lesions in man. Neuropsychologia, 20, 249-262.

Pietromonaco, P., \& Rook, K. (1987). Decision style in depression: The contribution of perceived risks versus benefits. Journal of Personality and Social Psychology, 52, 399-408.

Pribram, K. H. (1987). The subdivisions of the frontal cortex revisited. In E. Perecman (Ed.), The frontal lobes revisited (pp. 11-39). New York: IRBN Press.

Pribram, K. H., \& Tubbs, W. E. (1967, June 30). Short-term memory, parsing, and the primate frontal cortex. Science, 156, $1765-1767$.

Radloff, L. S. (1977). The CES-D scale: A self-report depression scale for research in the general population. Applied Psychological Measurement, 1, 385-401.

Rae, G. (1976). Table of $A^{\prime}$. Perceptual and Motor Skills, 42, 98. Reason, J. (1987). The psychology of mistakes: A brief review of planning failures. In J. Rasmussen, K. Duncan, \& J. Leplat (Eds.), New technology and human error (pp. 45-52). Chichester, England: Wiley.

Rezai, K., Andreasen, N. C., Alliger, R., Cohen, G., Swayze, V., \& O'Leary, D. S. (1993). The neuropsychology of the prefrontal cortex. Archives of Neurology, 50, 636-642.

Rueckert, L., \& Grafman, J. (1996). Sustained attention deficits in patients with right frontal lesions. Neuropsychologia, 34, $953-$ 963. 
Saint-Cyr, J. A., Taylor, A. E., \& Lang, A. E. (1988). Procedural learning and neostriatal dysfunction in man. Brain, 111, 941959.

Saint-Cyr, J. A., Taylor, A. E., Trépanier, L. L., \& Lang, A. E. (1992). The caudate nucleus: Head ganglion on the habit system. In G. Vallar, S. F. Cappa, \& C.-W. Wallesch (Eds.), Neuropsychological disorders associated with subcortical lesions (pp. 204-226). Oxford, England: Oxford University Press.

Saver, J. L., \& Damasio, A. R. (1991). Preserved access and processing of social knowledge in a patient with acquired sociopathy due to ventromedial frontal damage. Neuropsychologia, 29, 1241-1249.

Schmitter-Edgecombe, M., \& Rogers, W. A. (1997). Automatic process development following closed head injury. Neuropsychology, 11, 296-308.

Shallice, T. (1988). From neuropsychology to mental structure. New York: Cambridge University Press.

Shallice, T., \& Burgess, P. W. (1991). Higher-order cognitive impairments and frontal lobe lesions in man. In H. S. Levin, H. M. Eisenberg, \& A. L. Benton (Eds.), Frontal lobe function and dysfunction (pp. 125-138). New York: Oxford University Press.

Shallice, T., Burgess, P. W., Schon, F., \& Baxter, D. M. (1989). The origins of utilization behaviour. Brain, 112, 1587-1598.

Simon, H. A. (1975). The functional equivalence of problem solving skills. Cognitive Psychology, 7, 268-288.
Snyder, L. H., Batista, A. P., \& Andersen, R. A. (1997, March 13). Coding of intention in the posterior parietal cortex. Nature, 386 , $167-170$.

Sohlberg, M. M., Mateer, C. A., \& Stuss, D. T. (1993). Contemporary approaches to the management of executive control dysfunction. Journal of Head Trauma Rehabilitation, 8, 45-58.

Stuss, D. T., Alexander, M. P., \& Benson, D. F. (1997). Frontal lobe functions. In M. R. Trimble \& J. L. Cummings (Eds.), Contemporary behavioral neurology (pp. 169-187). Boston: Butterworth-Heinemann.

Stuss, D. T., \& Benson, D. F. (1986). The frontal lobes. New York: Raven Press.

Tranel, D., Anderson, S. W., \& Benton, A. (1994). Development of the concept of "executive function" and its relationship to the frontal lobes. In F. Boller \& J. Grafman (Eds.), Handbook of neuropsychology (Vol. 9, pp. 125-148). Amsterdam: Elsevier Science.

Vilkki, J., Virtanen, S., Surma-Aho, O., \& Servo, A. (1996). Dual task performance after focal cerebral lesions and closed head injuries. Neuropsychologia, 34, 1051-1056.

von Cramon, D. Y., \& Matthes-von Cramon, G. (1994). Back to work with a chronic dysexecutive syndrome? (A case report). Neuropsychological Rehabilitation, 4, 399-417.

Wiegersma, S., van der Scheer, E., \& Hijman, R. (1990). Subjective ordering, short-term memory, and the frontal lobes. Neuropsychologia, 28, 95-98. 


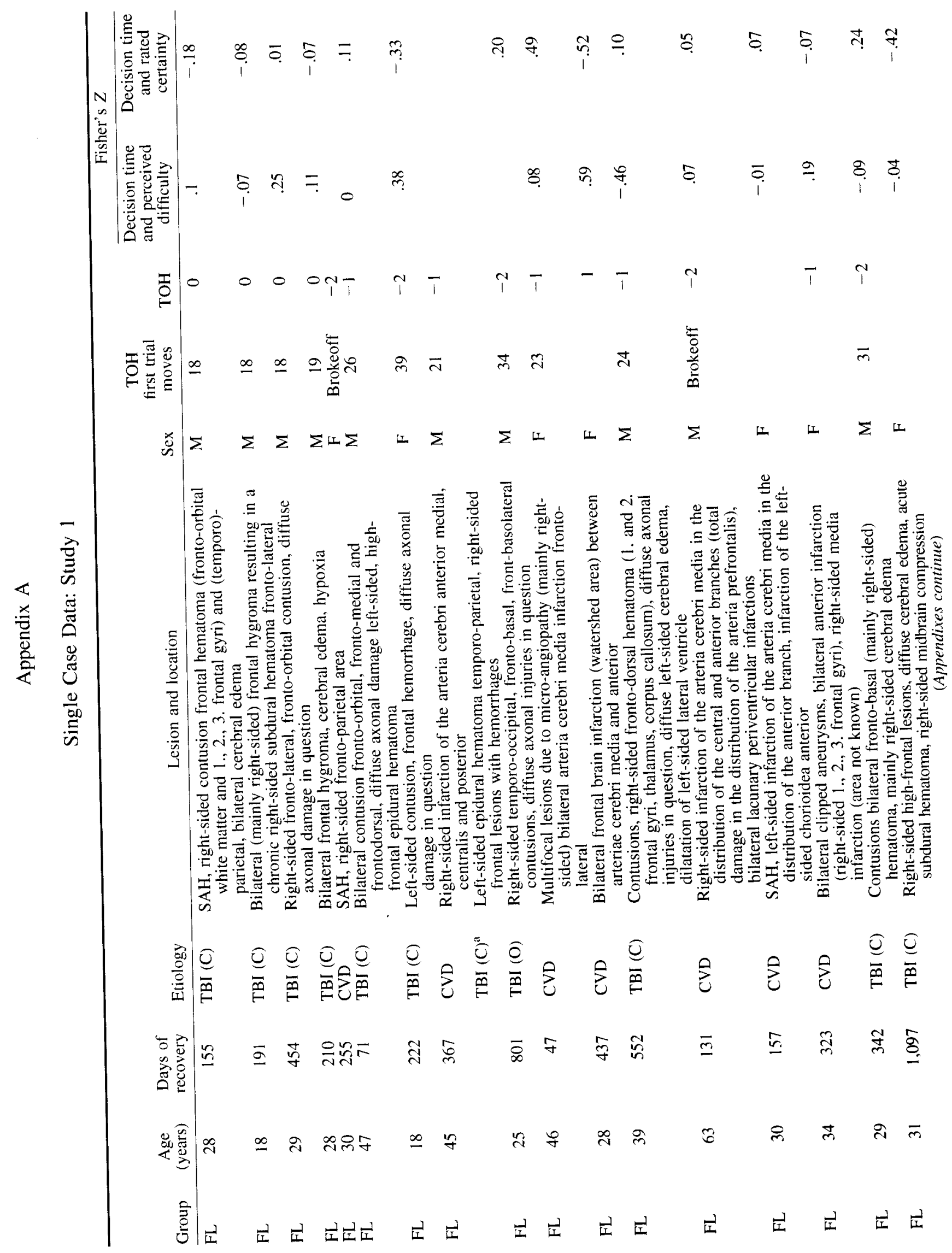




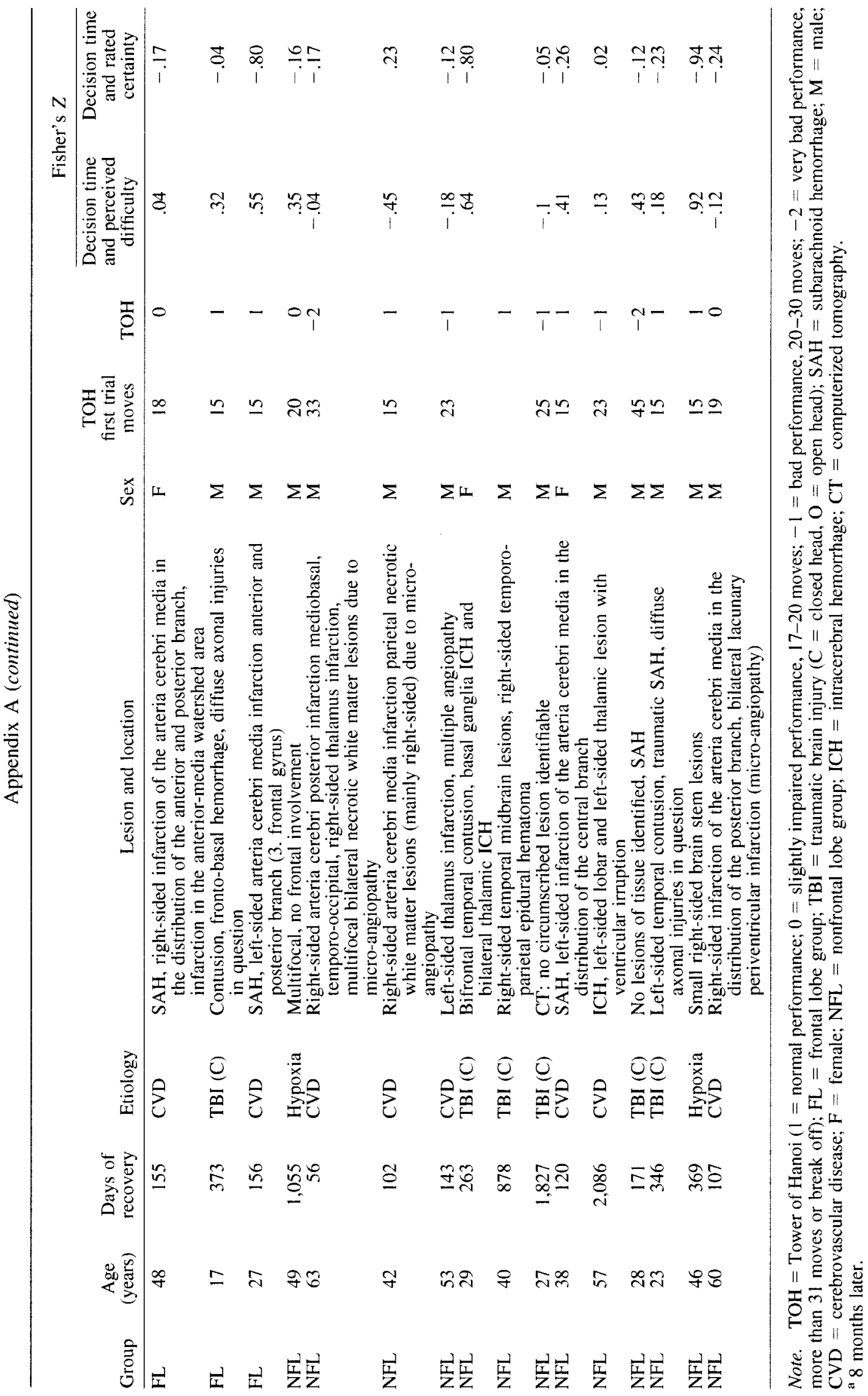




\section{Appendix B}

\section{Examples of Decision Problems in Study 1}

All problems were presented on a separate sheet of paper and were of equal text length ( 15 lines each).

\section{Problem of Medium Difficulty}

You are looking for a new accommodation as the place you are living in right now is too far away from your work place. Your "old" apartment is a very nice and quiet place. After having looked for a new flat for months you have now been offered a place that is not expensive and much closer to your work place. Using public transport you could be at work in about 5 minutes time. However, it is located at a very noisy street with lots of traffic.

On the one hand, your long experiences in looking for a place to live tell you that it will not be easy to get a better, more suitable offer. On the other hand, you hesitate to submit yourself to moving into a new place if you do not really intend to stay there for quite some time.

Will you move to the new apartment or stay in your "old" place?
I take the new apartment.

I stay in the old place.

\section{Problem of High Difficulty}

For some years you have been working for this company. Most of the time you enjoyed doing your work. Now you have got the chance to improve in your career. You have been offered a higher position in one of the company's other branches. In your present position you have nice colleagues and you feel sorry to part with them, all the more as you have heard that the working atmosphere in the other branch is rather bad. However, you would earn considerably more money, and in the branch you are working at now there are no prospects of promotion within the next two years. At the same time you are wondering whether you will be able to meet the higher demands of the new position.

Will you accept the offered new position or stay in your previous position?

I accept the new position.

I stay in the previous position.

(Appendixes continue) 


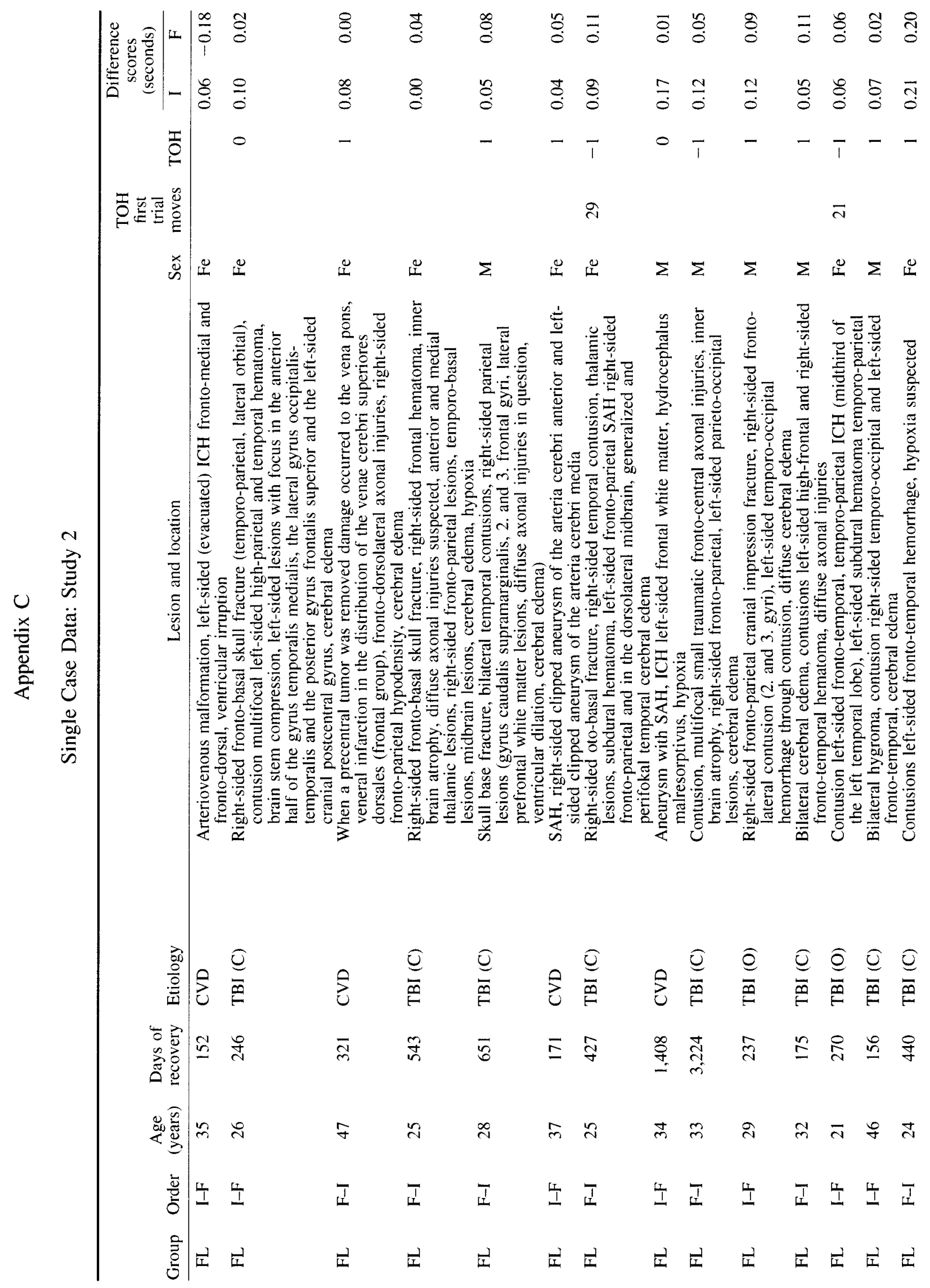




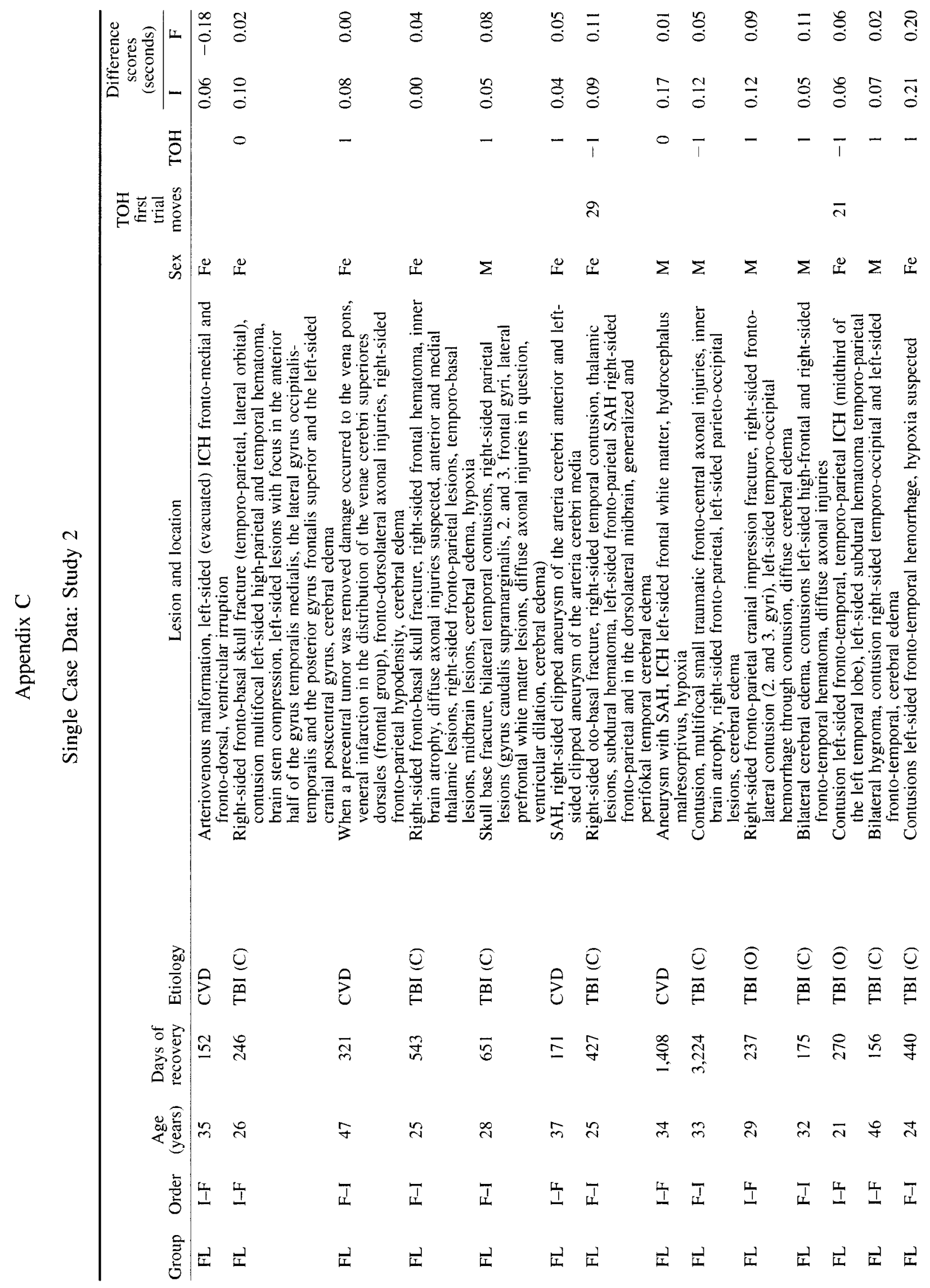




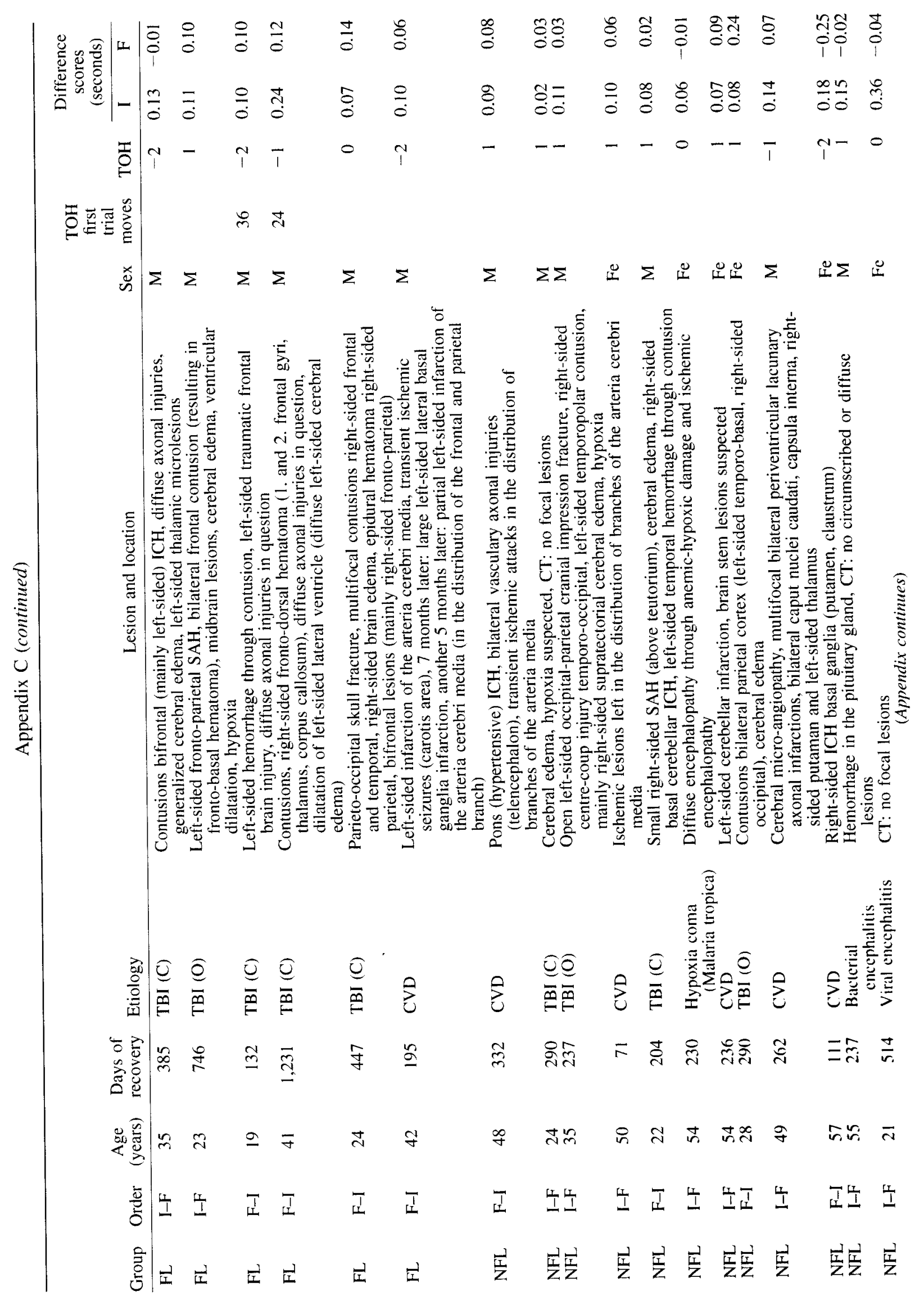




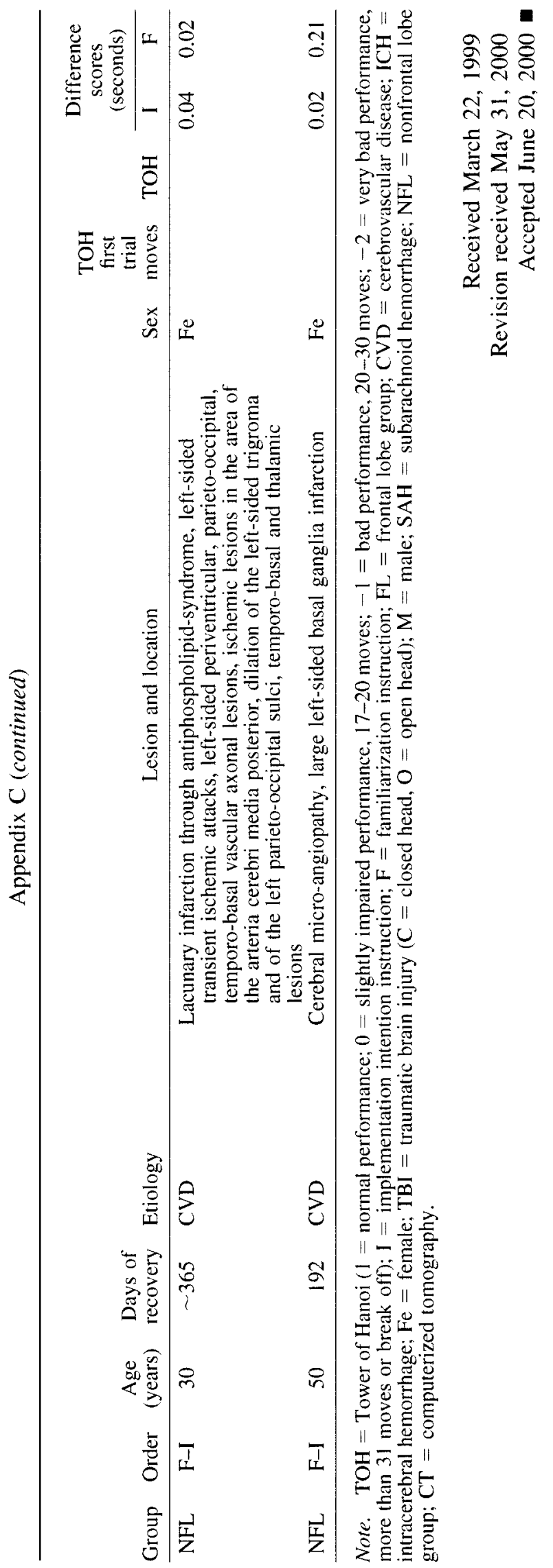

